\title{
Resveratrol Differentially Regulates NAMPT and SIRT1 in Hepatocarcinoma Cells and Primary Human Hepatocytes
}

\author{
Susanne Schuster ${ }^{1 *}$, Melanie Penke ${ }^{1}$, Theresa Gorski ${ }^{1}$, Stefanie Petzold-Quinque ${ }^{1}$, Georg Damm ${ }^{2}$, \\ Rolf Gebhardt ${ }^{3}$, Wieland Kiess' ${ }^{1}$, Antje Garten'
}

1 Center for Pediatric Research Leipzig, University Hospital for Children and Adolescents, Faculty of Medicine, University of Leipzig, Leipzig, Germany, 2 Department of General-, Visceral- and Transplantation Surgery, Charité University Medicine Berlin, Berlin, Germany, $\mathbf{3}$ Institute of Biochemistry, Faculty of Medicine, University of Leipzig, Leipzig, Germany

\begin{abstract}
Resveratrol is reported to possess chemotherapeutic properties in several cancers. In this study, we wanted to investigate the molecular mechanisms of resveratrol-induced cell cycle arrest and apoptosis as well as the impact of resveratrol on NAMPT and SIRT1 protein function and asked whether there are differences in hepatocarcinoma cells (HepG2, Hep3B cells) and non-cancerous primary human hepatocytes. We found a lower basal NAMPT mRNA and protein expression in hepatocarcinoma cells compared to primary hepatocytes. In contrast, SIRT1 was significantly higher expressed in hepatocarcinoma cells than in primary hepatocytes. Resveratrol induced cell cycle arrest in the S- and G2/M- phase and apoptosis was mediated by activation of p53 and caspase-3 in HepG2 cells. In contrast to primary hepatocytes, resveratrol treated HepG2 cells showed a reduction of NAMPT enzymatic activity and increased p53 acetylation (K382). Resveratrol induced NAMPT release from HepG2 cells which was associated with increased NAMPT mRNA expression. This effect was absent in primary hepatocytes where resveratrol was shown to function as NAMPT and SIRT1 activator. SIRT1 inhibition by EX527 resembled resveratrol effects on HepG2 cells. Furthermore, a SIRT1 overexpression significantly decreased both p53 hyperacetylation and resveratrol-induced NAMPT release as well as S-phase arrest in HepG2 cells. We could show that NAMPT and SIRT1 are differentially regulated by resveratrol in hepatocarcinoma cells and primary hepatocytes and that resveratrol did not act as a SIRT1 activator in hepatocarcinoma cells.
\end{abstract}

Citation: Schuster S, Penke M, Gorski T, Petzold-Quinque S, Damm G, et al. (2014) Resveratrol Differentially Regulates NAMPT and SIRT1 in Hepatocarcinoma Cells and Primary Human Hepatocytes. PLoS ONE 9(3): e91045. doi:10.1371/journal.pone.0091045

Editor: Matias A. Avila, University of Navarra School of Medicine and Center for Applied Medical Research (CIMA), Spain

Received June 12, 2013; Accepted February 9, 2014; Published March 6, 2014

Copyright: ( $) 2014$ Schuster et al. This is an open-access article distributed under the terms of the Creative Commons Attribution License, which permits unrestricted use, distribution, and reproduction in any medium, provided the original author and source are credited.

Funding: The work was supported by German Research Foundation (DFG) KFO 152 "Atherobesity" (to WK), DDG (Deutsche Diabetes Gesellschaft) (to SS and AG) and by LIFE ( Leipzig Research Center for Civilization Diseases, University of Leipzig ) (to WK and SS). LIFE is funded by means of the European Union, by the European Regional Development Fund (ERDF) and by means of the Free State of Saxony within the framework of the excellence initiative. The "virtual liver" program is funded by the German Federal Ministry of Education and Research. We also acknowledge support from the German Research Foundation (DFG) and Leipzig University within the program of Open Access Publishing. The funders had no role in study design, data collection and analysis, decision to publish, or preparation of the manuscript.

Competing Interests: The authors have declared that no competing interests exist.

*E-mail: Susanne.Schuster@medizin.uni-leipzig.de

\section{Introduction}

Resveratrol, a dietary polyphenol, is reported to possess both chemopreventive and chemotherapeutic properties in several cancers [1]. In 1997, Jang and colleagues published a seminal paper reporting that resveratrol is able to inhibit carcinogenesis in all three stages (initiation, promotion and progression) [2]. Resveratrol was shown to inhibit cell proliferation, induce apoptosis and cell cycle arrest in different cancer types and cancer cell lines [3-9]. However, only one study compared the apoptotic effects of resveratrol on cancer and normal cells. Baarine et al. found apoptotic effects in murine tumoral cardiac cells which were absent in normal cardiomyocytes [8]. The molecular mechanisms are currently not completely understood. SIRT1 has originally been described as a target of resveratrol [10] although some of the data are still controversial, especially concerning resveratrol acting as SIRT1 activator in cancer cells [11-13]. SIRT1 belongs to the NAD (Nicotinamide adenine dinucleotide) dependent histone deacetylases, called sirtuins. SIRT1 is involved in many cellular pathways, such as cellular survival, apoptosis, cellular stress response and energy metabolism. An increased expression of SIRT1 has been reported in a variety of human cancers, including prostate, ovarian, gastric and colorectal cancer. The role of SIRT1 in tumorigenesis is still controversially discussed. SIRT1 has been shown to act as both tumor promoter and tumor suppressor $[14,15]$. SIRT1 was shown to deacetylate the tumor-suppressor protein p53 on lysine residue 382 leading to its inhibition and subsequent tumorigenesis $[16,17]$. Thus, the inhibition of SIRT1 would induce cell death of cancer cells by activating and acetylating p53.

It is known that cancer cells have increased energy demands because of their rapid cell proliferation and increased DNA repair [18]. NAD is required for both processes [19] and regulates crucial biological processes, including transcription, cell cycle progression, DNA repair and metabolic pathways [20,21]. Therefore, cancer cells have a higher rate of NAD turnover than normal cells. The regeneration of intracellular NAD pools is regulated by NAMPT (Nicotinamide phosphoribosyltransferase). NAMPT can be found intracellularly (iNAMPT) and extracellularly (eNAMPT). However, neither structural differences between these forms nor the 
mechanism of NAMPT secretion are known so far. As an intracellular protein, NAMPT catalyses the rate-limiting step in the NAD salvage pathway starting from nicotinamide and yielding nicotinamide mononucleotide (NMN) which is then converted to NAD [22-25]. Some cancer cells maintain intracellular NAD levels by overexpressing NAMPT which has been shown in different cancer types, such as colorectal and breast cancer [2628]. The expression and regulation of intracellular NAMPT in hepatocarcinoma cells has not been characterized so far. NAMPT inhibition by its highly specific inhibitor FK866 induces apoptosis and/or autophagy in tumor cells [29-32]. Moreover, previous studies pointed out that inhibition of NAMPT enzymatic activity by FK866 or inhibition of SIRT1 activity decreased proliferation and triggered cell death in cancer cells which was associated with increased acetylation of p53 (K382) [16,17,33,34].

Here we investigated the molecular mechanisms of resveratrolinduced apoptotic effects on hepatocarcinoma cells and noncancerous human hepatocytes and asked whether NAMPT and SIRT1 are differentially regulated in hepatocarcinoma cells and non-cancerous human hepatocytes.

\section{Materials and Methods}

\section{Ethics Statement}

Non-cancerous primary human hepatocytes were supplied by the "virtual liver" program (German Federal Ministry of Education and Research) and the non profit foundation HTCR, including the informed patient's consent. The use of human hepatocytes for research purposes was approved by the local ethics committee of the Charite University Berlin. Written informed consent was obtained from all patients. The Charité University Berlin institutional review board specifically approved this study.

\section{Material}

Cell culture media, supplements and antibiotics were obtained from PAA (Cölbe, Germany) or Invitrogen (Karlsruhe, Germany). Resveratrol (trans isomer), nicotinamide and camptothecin were purchased from Sigma-Aldrich (Munich, Germany). FK866 was kindly provided by TopoTarget A/S, Copenhagen, Denmark. EX527 was obtained from Cayman Chemical (Ann Arbor, USA), InSolution Trichostatin A (TSA) and etoposide were purchased from Merck Millipore (Darmstadt, Germany). Flag-SIRT1 expression vector was obtained from Addgene (Addgene plasmid 1791) [35].

\section{Cell Culture}

HepG2 cells were purchased from Leibniz Institute DSMZ (German Collection of Microorganisms and Cell cultures) and Hep3B cell were kindly provided by Prof. Dr. Kurt Engeland
(Molecular Oncology, Medical School, University of Leipzig). Cells were maintained in MEM medium supplemented with $10 \%$ fetal bovine serum (FBS) and $2 \mathrm{mmol} / \mathrm{L}$ glutamine and $100 \mathrm{IU}$ penicillin and $100 \mu \mathrm{g} / \mathrm{mL}$ streptomycin. Primary human hepatocytes were isolated and cultured essentially as described [36]. Cells were seeded in Williams' Medium $\mathrm{E}$ containing $2 \mathrm{mmol} / \mathrm{L}$ glutamine, $10^{-7} \mathrm{~mol} / \mathrm{L}$ dexamethansone, $100 \mathrm{IU}$ penicillin and $100 \mu \mathrm{g} / \mathrm{mL}$ streptomycin and $10 \% \mathrm{FBS}$. All cells were grown at $37^{\circ} \mathrm{C}$ in a humidified atmosphere of $95 \%$ air and $5 \% \mathrm{CO}_{2}$.

\section{Cell Treatments}

Resveratrol was dissolved in $100 \%$ ethanol to create a stock solution of $100 \mathrm{mM}$. Cells were stimulated with 10/25/50/ $100 \mu \mathrm{M}$ resveratrol and the equivalent amount of solvent control (ethanol) to exclude solvent-mediated effects. To inhibit SIRT1 and deacetylases other than histone deacetylases class III, we used the compound EX527 $[20 \mu \mathrm{M}]$, a cell-permeable selective inhibitor of SIRT1 dissolved in DMSO [37] and $1 \mu \mathrm{M}$ of TSA which were added to the incubation medium.

\section{Measurement of Cell Viability and Apoptosis}

To investigate the effects on proliferation and cell viability, we used the commercial Cell Proliferation Reagent WST-1 (Roche, Grenzach-Wyhlen, Germany) and measured absorbance at $450 \mathrm{~nm}$. To evaluate the effects of resveratrol on apoptosis the number of apoptotic cells was measured by flow cytometry using the FITC Annexin V Apoptosis Detection Kit (BD Pharmingen, Franklin Lakes, USA). Adherent and floating cells were used. 5$10 \mu \mathrm{L}$ of Annexin V-FITC (An) and $2 \mu \mathrm{L}$ of propidium iodide (PI) were added to the cell suspension. Samples were analysed using a Beckton-Dickinson FACS LSRII. As positive control, apoptosis was induced via camptothecin $[2 \mu \mathrm{M}]$ and etoposide [85 $\mu \mathrm{M}]$ for $24 \mathrm{~h}$. An+ and double-stained An+/PI+ cells were considered apoptotic. To exclude cytotoxic effects of resveratrol, we used supernatant of HepG2 cells and primary human hepatocytes to measure the release of the enzyme, adenylate kinase, from damaged cells. Therefore, we used the ToxiLight ${ }^{\mathrm{TM}}$ Nondestructive Cytotoxicity BioAssay Kit (Lonza, Cologne, Germany).

\section{Cell Cycle Distribution Analysis}

PI staining was used to analyse DNA content and cell cycle distribution. After cell treatment, adherent and floating cells were harvested and fixed with $2 \mathrm{~mL}$ of $70 \%$ ethanol $\left(4^{\circ} \mathrm{C}\right)$. The cell pellet was resuspended in $50 \mu \mathrm{L}$ PBS with $3.3 \mu \mathrm{L}$ RNase A $[30 \mathrm{mg} / \mathrm{mL}], \quad 450 \mu \mathrm{L}$ FACS-buffer $(\mathrm{PBS}+2 \%$ FBS) and PI [50 $\mu \mathrm{g} / \mathrm{mL}]$ were added to the flow cytometry tubes. Cells were analysed using a Beckton-Dickinson FACS LSRII by measuring the PI signal in the FL2 channel.

Table 1. Sequences of Primer and Probes used for real-time PCR (TaqMan).

\begin{tabular}{llll}
\hline & & \\
\hline Target & Forward Primer & Reverse Primer & Probe \\
\hline NAMPT & GCA GAA GCC GAG TTC AAC ATC & TGC TTG TGT TGG GTG GAT ATT G & TGG CCA CCG ACT CCT ACA AGG TTA CTC AC \\
beta-ACTIN & CGA GCG CGG CTA CAG CTT & CCT TAA TGT CAC GCA CGA TTT & ACC ACC ACG GCC GAG CGG \\
TBP & TTG TAA ACT TGA CCT AAA GAC CAT TGCTTC GTG GCT CTC TTA TCC TCA TG & AAC GCC GAA TAT AAT CCC AAG CGG TTT G \\
HPRT & GGC AGT ATA ATC CAA AGA TGG TCA A & GTC TGG CTT ATA TCC AAC ACT TCG T & CAA GCT TGC TGG TGA AAA GGA CCC C \\
p21 & CGAAGTCAGTTCCTGTGGAG & CATGGGTCTGACGGACAT & - \\
\hline
\end{tabular}

NAMPT (nicotinamide phosphoribosyltransferase, also known as PBEF, visfatin); p21; housekeeping genes beta-ACTIN, TBP (TATA-box-binding protein) and HPRT (hypoxanthine phophoribosyltransferase).

doi:10.1371/journal.pone.0091045.t001 
A

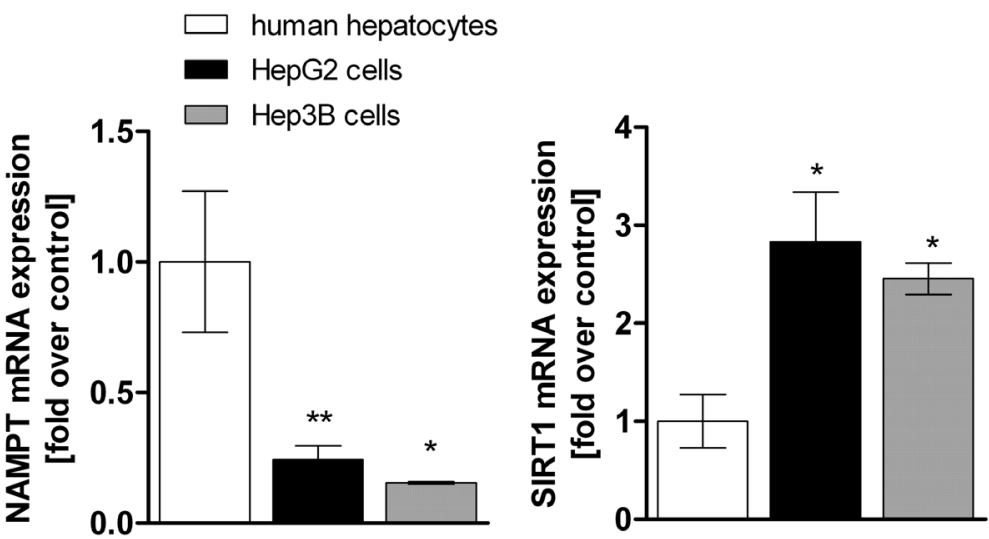

B

\section{human}

\section{hepatocytes HepG2 cells Hep3B cells}

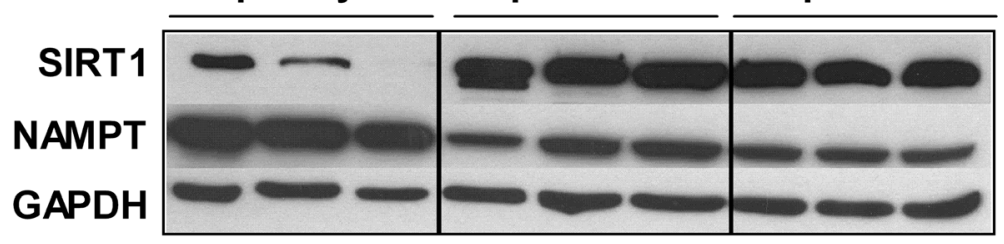

C

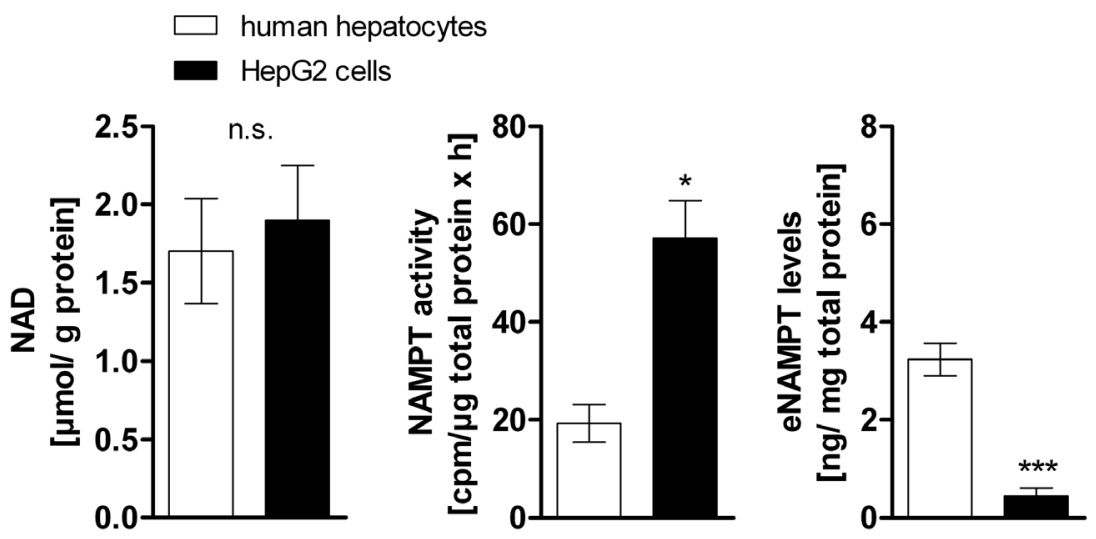

Figure 1. NAMPT and SIRT1 expression in hepatocarcinoma cells and primary human hepatocytes. A) mRNA expression and B) protein expression of NAMPT and SIRT1 in primary human hepatocytes $(n=7)$, HepG2 cells $(n=8)$ and Hep3B cells $(n=3)$. Representative Western Blot is shown out of three independent experiments. Measurement of $C$ ) intracellular NAD levels (left panel, primary hepatocytes $n=4$, HepG2 cells $n=6$ ), basal NAMPT enzymatic activity (middle panel, primary hepatocytes $n=3$, HepG2 cells $n=4$ ) and extracellular NAMPT (eNAMPT) levels (right panel, primary hepatocytes $n=3$, HepG2 cells $n=6$ ) in primary human hepatocytes and HepG2 cells. Data are shown as mean \pm SEM. Difference between two groups was evaluated using unpaired Student's $t$-test $\left({ }^{*} \mathrm{p}<0.05,{ }^{* *} \mathrm{p}<0.01,{ }^{* * *} \mathrm{p}<0.001\right)$.

doi:10.1371/journal.pone.0091045.g001

\section{Reverse Transcription-quantitative Real-time PCR (RTqPCR)}

To measure mRNA expression, total RNA was extracted using the RNeasy Mini Kit (Qiagen, Hilden, Germany) according to the manufacturer's instructions. Reverse transcription was performed using 200 U M-MLV reverse transcriptase (Invitrogen, Karlsruhe, Germany) per $500 \mathrm{ng}$ or $1 \mu \mathrm{g}$ total RNA with random hexamer $[\mathrm{p}(\mathrm{dN}) 6]$ primers. mRNA expression was quantified by real-time PCR with TaqMan probe based (Eurogentec, Cologne, Germany) or SYBR green based (Primerdesign, Southampton, UK) gene expression assay on the ABI 7500 Sequence Detection System (Applied Biosystems, Darmstadt, Germany). The housekeeping genes TATA-box-binding protein (TBP), hypoxanthine phosphoribosyltransferase (HPRT) or beta-ACTIN were quantified simultaneously. Sequence information of primers and probes are given in Table 1. For standardization of gene expression, the target gene amount was normalized to the mean of the housekeeping gene expression in each sample. 
A

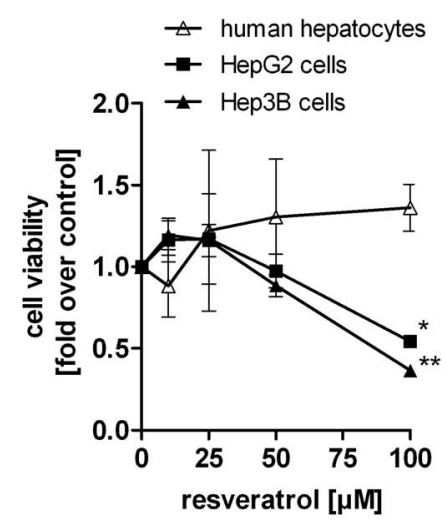

C

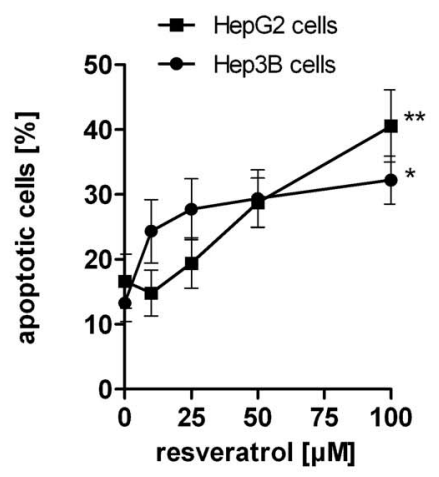

B

control

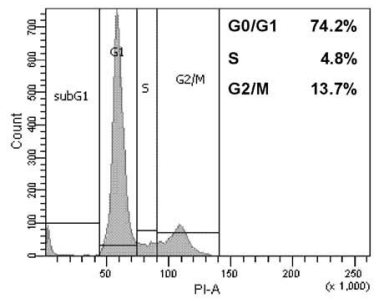

Resv. $50 \mu \mathrm{M}$

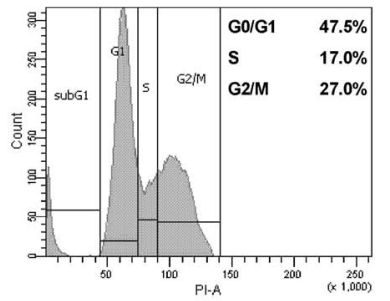

D

\section{control}

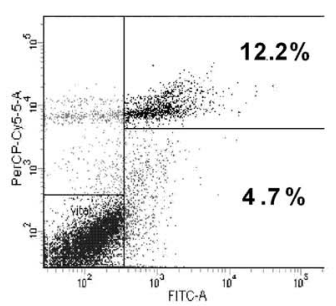

Resv. $50 \mu \mathrm{M}$

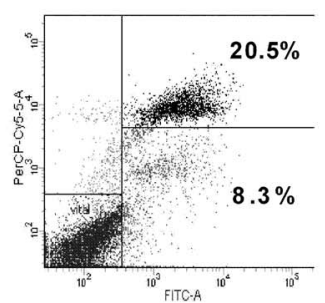

Resv. $25 \mu \mathrm{M}$

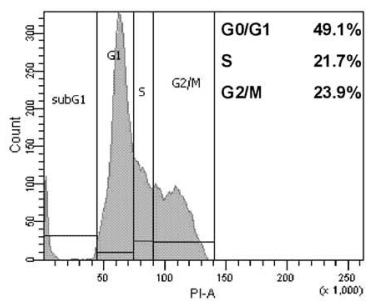

Resv. $100 \mu \mathrm{M}$

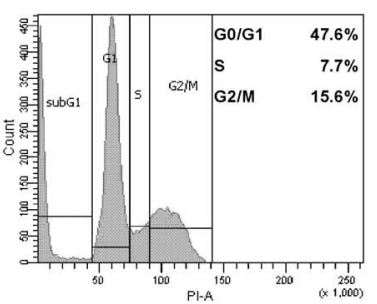

Resv. $25 \mu \mathrm{M}$

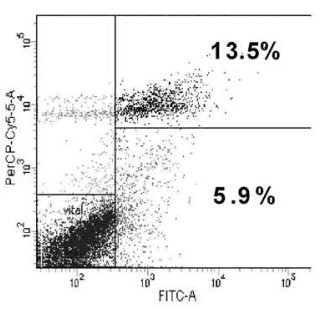

Resv. $100 \mu \mathrm{M}$

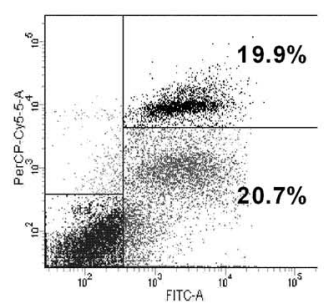

Figure 2. Resveratrol reduces cell proliferation and induces cell cycle arrest and apoptosis in hepatocarcinoma cells which is absent in primary human hepatocytes. Cell viability of A) primary human hepatocytes $(n=2)$, HepG2 and Hep3B cells $(n=3)$ after stimulation with resveratrol for $24 \mathrm{~h}$. Data were normalised to serum-free medium control which was set 1. B) Cell cycle distribution of HepG2 cells treated with resveratrol for $24 \mathrm{~h}$. A representative result is shown out of three independent experiments. A representative dot plot is given in Fig. S2B. C) Annexin V/PI apoptosis assay of HepG2 $(n=3)$ and Hep3B cells $(n=3)$ treated with resveratrol for 24 h. D) A representative dot plot of the Annexin/PI staining in HepG2 cells is shown including the mean percentage of $A n+$ and double $A n+/ P I+$ cells of three independent experiments. Data are shown as mean \pm SEM and statistical analysis was performed using one-way ANOVA and the Bonferroni post hoc test ( ${ }^{*} p<0.05 ;{ }^{* *} p<0.01$ compared to serumfree medium).

doi:10.1371/journal.pone.0091045.g002

\section{Protein Extraction and Immunoblotting}

For protein analyses, cells were lysed in modified RIPA buffer (50 mM TrisHCl pH 7.4; $1 \%$ NP-40; $0.25 \%$ sodium deoxycholate; $1 \times$ Roche complete proteases inhibitor cocktail; $1 \mathrm{mM}$ EDTA; $1 \mathrm{mM}$ sodium orthovanadate; $1 \mathrm{mM}$ sodium fluoride; $5 \mathrm{mM}$ nicotinamide; $5 \mu \mathrm{M}$ TSA, $1 \mathrm{mM}$ sodium butyrate) and separated by SDS-PAGE (8-15\%). Protein concentration of lysates was measured by BCA protein assay (Pierce, Thermo Scientific). After transfer to nitrocellulose membranes (Millipore, Bedford, MA, USA), blots were blocked with $5 \%(\mathrm{w} / \mathrm{v})$ non-fat dry milk in $1 \times$ TBS buffer containing $0.1 \%$ Tween 20 (TBS-T). Primary antibodies used for immunoblotting included antiNAMPT clone OMNI 379 (1:5000) (Cayman Chemical, Ann Arbor, MI, USA), anti- acetylated p53 (K382) (1:1000), anti-p53 (1:1000), anti-p53 (1C12) (1:1000), anti-phospho-p53 (Ser15) 
A

HepG2 cells

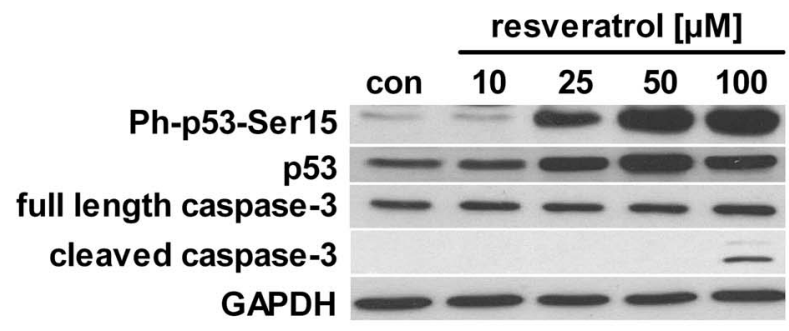

B

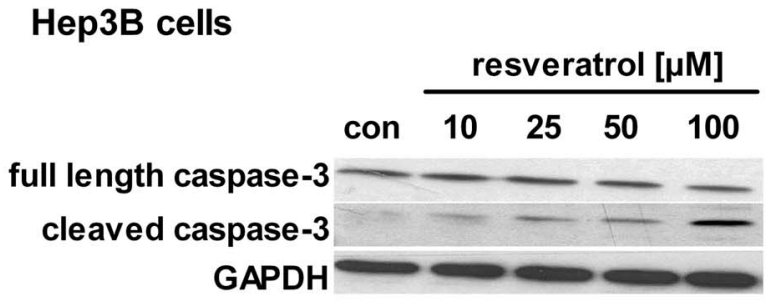

C

primary hepatocytes

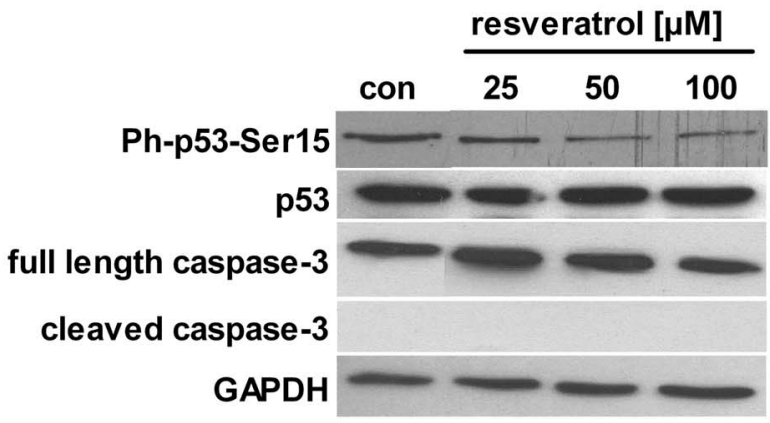

Figure 3. Resveratrol activates apoptotic mechanisms in hepatocarcinoma cells. Cells were treated with resveratrol or serum-free medium (con) for $24 \mathrm{~h}$. Activation of p53 through phosphorylation at serine residue 15 and cleavage of caspase-3 in A) HepG2 cells, B) Hep3B cells and C) primary human hepatocytes were analysed by Western Blot. GAPDH was used as loading control. One representative blot out of at least 3 independent experiments is shown. doi:10.1371/journal.pone.0091045.g003

(1:1000), anti-SIRT1 (D379) (1:1000), anti-p21 (1:1000), anti-Bax (1:1000), anti-caspase3 (1:500), anti- cleaved caspase3 (1:500) (Cell Signaling, Beverly, MA, USA) and anti-GAPDH (MerckMillipore, Schwalbach, Germany). Secondary antibodies were purchased from DAKO (Hamburg, Germany). Immunoblotting for GAPDH was performed to verify equivalent amounts of loaded protein. Detection was performed using enhanced chemiluminescence. Densitometric analysis was performed using ImageJ 1.41 Software (NIH, USA).

\section{Measurement of NAMPT Release}

NAMPT concentration in supernatants of HepG2 cells and primary hepatocytes was quantified using the human extracellular NAMPT/PBEF/Visfatin ELISA Kit (AdipoGen Inc., Seoul,
South Korea), respectively, according to manufacturer's instructions. NAMPT concentration was normalised to the corresponding total protein amount in each sample. For semiquantitative measurements, NAMPT levels were detected by using supernatant of cultured cells for Western Blot analysis.

\section{NAMPT Enzymatic Activity}

NAMPT activity was measured by the conversion of ${ }^{14} \mathrm{C}$ labelled nicotinamide to ${ }^{14} \mathrm{C}-\mathrm{NMN}$ using a method previously described [38]. For preparation of lysates, cells were harvested and resuspended in $100 \mu \mathrm{L}$ of $0.01 \mathrm{~mol} / \mathrm{L}$ sodium phosphate buffer, $\mathrm{pH} 7.4$, frozen at $-80^{\circ} \mathrm{C}$ for $24 \mathrm{~h}$ and thawed at room temperature. Cell debris was removed by centrifugation at $23,000 \mathrm{rcf}, 90 \mathrm{~min}$ at $0^{\circ} \mathrm{C}$. Protamine sulphate solution $(1 \%$ in NaHPO4 buffer) was added to the supernatant $(70 \mu \mathrm{L} / \mathrm{mL}$ supernatant) to precipitate DNA by incubation on ice for $15 \mathrm{~min}$. After centrifugation at 23,000 ref, $30 \mathrm{~min}$ at $0^{\circ} \mathrm{C}$, aliquots of the supernatant were stored at $-80^{\circ} \mathrm{C}$. Lysates $(50 \mu \mathrm{g})$ were added to $50 \mu \mathrm{L}$ reaction mix $(50 \mathrm{mmol} / \mathrm{L}$ TrisHCl; $2 \mathrm{mmol} / \mathrm{L}$ ATP; $5 \mathrm{mmol} / \mathrm{L} \mathrm{MgCl} 2 ; 0.5 \mathrm{mmol} / \mathrm{L} \mathrm{PRPP} ; 6.2 \mu \mathrm{mol} / \mathrm{L}{ }^{14} \mathrm{C}-$ nicotinamide; American Radiolabelled Chemicals, St. Louis; MO, USA) and incubated at $37^{\circ} \mathrm{C}$ for $1 \mathrm{~h}$. Optimal conditions for the NAMPT activity assay (amount of total protein, incubation time, $\mathrm{pH}$ value) were determined (Fig. S1A,B,C). For measuring extracellular NAMPT activity we used supernatant of HepG2 cells and concentrated it 80-fold using Amicon Ultra Centrifugal Filter Units (Ultracel-50k) (Millipore). Then, $10 \mu \mathrm{l}$ of concentrated supernatant was used for the enzyme assay reaction mix and incubated for $2 \mathrm{~h}$ at $37^{\circ} \mathrm{C}$. The NAMPT enzymatic reaction was terminated by mixing with $2 \mathrm{~mL}$ of acetone. The mixture was then transferred onto acetone-pre-soaked glass microfiber filters (GF/A Ø 24 mm; Whatman, Maidstone, UK). After rinsing with $2 \times 1 \mathrm{~mL}$ acetone, filters were dried, transferred into vials with $6 \mathrm{~mL}$ scintillation cocktail (Betaplate Scint, PerkinElmer, Waltham, MA, USA) and radioactivity of ${ }^{14} \mathrm{C}-\mathrm{NMN}$ was quantified in a liquid scintillation counter in counts per minute (cpm) (Wallac 1409 DSA, PerkinElmer). NAMPT activity was normalised to total protein concentration as measured by the BCA protein assay. The validity of the assay was evaluated by adding the specific NAMPT inhibitor, FK866 (Fig. S1C). FK866 induced a dosedependent decrease in NAMPT activity with an $\mathrm{IC}_{50}$ value of $8.2 \mathrm{nM}$.

\section{NAD Measurements}

Concentrations of NAD from whole-cell extracts were quantified by High-performance liquid chromatography (HPLG) and the NAD/NADH assay kit (EnzyChrom NAD/NADH Assay Kit, Biotrend, Köln, Germany), applied according to manufacturer's instructions. HPLC analysis was performed with Chromaster Purospher STAR RP-18 endcapped $3 \mu \mathrm{m}$ Hibar RT 150-3 HPLC column (Merck). Briefly, cultured cells were extracted in $1 \mathrm{M}$ $\mathrm{HClO}_{4}$ and neutralized in $3 \mathrm{M} \mathrm{K} \mathrm{KO}_{3}$ on ice as described previously [39]. After centrifugation for $10 \mathrm{~min}$ at $18,000 \mathrm{rcf}$ $\left(4^{\circ} \mathrm{C}\right)$, the supernatant was filtered and loaded onto the column. For NAD measurement, the HPLC was run at a flow rate of 0,4 $\mathrm{ml} / \mathrm{min}$ with $100 \%$ buffer A from $0-5 \mathrm{~min}$, a linear gradient to $95 \%$ Buffer A/5\% Buffer B (100\% methanol) from 5-6 min, 95\% Buffer A/5\% Buffer B from 6-11 min, a linear gradient to 85\% Buffer A/15\% Buffer B from 11-12 min, 85\% Buffer A/15\% Buffer B from 12-16 min, and a linear gradient to $100 \%$ Buffer A from 16-17 min. NAD was eluted as a sharp peak at $15 \mathrm{~min}$ and quantitated based on the peak area compared to a standard curve and normalised to protein content of cultured cells. 
A

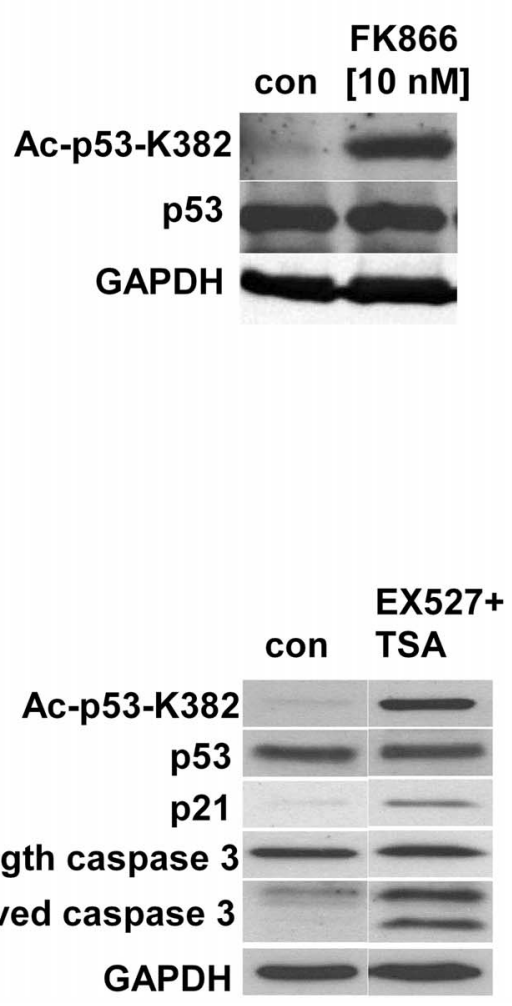

C

Con
p53
Ac-p53-K382
full length caspase 3
cleaved caspase 3
GAPDH

B

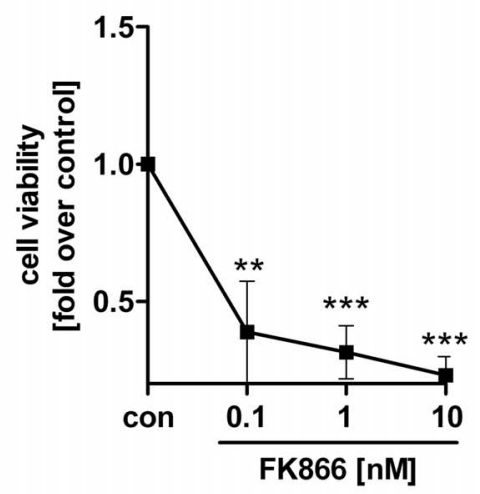

Figure 4. Effects of FK866 and EX527 on p53 acetylation and cell viability in HepG2 cells. Cells were stimulated with FK866 [10 nM] or EX527+TSA [20 $\mu \mathrm{M}$ EX527+1 $\mu \mathrm{M}$ TSA] in serum-free medium (con). Cells treated with A) FK866 and expression of acetylated p53 (K382) after 24 h. B) Cell viability of HepG2 cells after stimulation with FK866 for $48 \mathrm{~h}$ measured by WST- 1 assay $(n=4)$. Data were normalised to serum-free medium (con) which was set $1{ }^{* *} p<0.01 ;{ }^{* * *} p<0.001$ compared to serum free medium). C) Expression of acetylated p53 (K382), p21 protein and cleavage of caspase-3 were analysed in HepG2 cells treated with EX527+TSA for 24 h. GAPDH was used as loading control. One representative blot out of 3 independent experiments is shown.

doi:10.1371/journal.pone.0091045.g004

\section{Plasmid Transfection}

Transfection was conducted using NEON Transfection System (100 $\mu \mathrm{l} \mathrm{Kit,} \mathrm{invitrogen)} \mathrm{according} \mathrm{to} \mathrm{the} \mathrm{manufacturer's} \mathrm{manual.}$ Briefly, HepG2 cells were splitted 1:3 one day before transfection. Cells were transiently transfected with pECE-Flag-SIRT1 $(2 \mu \mathrm{g}$ DNA $/ 0.5 \times 10^{6}$ cells) or the empty vector (mock-control). After $24 \mathrm{~h}$ of transfection, medium was changed for a further $24 \mathrm{~h}$ resveratrol-containing medium at $37^{\circ} \mathrm{C}$.

\section{Statistical Analyses}

Data are presented as mean \pm SEM. Data were analysed for statistical significance by one-way analysis of variance (ANOVA) followed by Bonferroni post hoc test. Differences between two groups were evaluated using unpaired Student's $t$-test. All analyses were performed using GraphPad Prism 5 software (GraphPad Software, Inc., San Diego, USA). The level of significance for all comparisons was set at $\mathrm{p}<0.05$.

\section{Results}

NAMPT and SIRT1 are Differentially Expressed in Hepatocarcinoma Cells and Primary Human Hepatocytes

The expression levels of NAMPT and SIRT1 were evaluated using qPCR and Western Blot analysis. Our data revealed that NAMPT expression is lower in HepG2 $(-75.6 \% \pm 5.2 \%)$ and Hep3B cells $(-84.6 \% \pm 0.5 \%)$ compared to non-cancerous primary human hepatocytes (Fig. 1A,B). In contrast, the
NAD-dependent deacetylase SIRT1 is significantly higher expressed in both cancer cell lines compared to primary human hepatocytes (HepG2 cells 2.8-fold, Hep3B cells 2.5-fold) (Fig. 1A,B). Intracellular NAD levels in HepG2 cells and primary hepatocytes were not significantly different (HepG2 cells $1.9 \pm 0.3 \mu \mathrm{mol} \mathrm{NAD} / \mathrm{g}$ protein compared to $1.7 \pm 0.3 \mu \mathrm{mol}$ $\mathrm{NAD} / \mathrm{g}$ protein in primary human hepatocytes) (Fig. 1C, left panel). A comparison of the NAMPT enzymatic activity in HepG2 cells and primary human hepatocytes showed a 3-fold higher $(\mathrm{p}<0.05)$ enzymatic activity of NAMPT in HepG2 cells $(57.2 \pm 7.7 \mathrm{cpm} / \mu \mathrm{g}$ protein $\times \mathrm{h})$ than in primary human hepatocytes $(19.3 \pm 3.8 \mathrm{cpm} / \mu \mathrm{g}$ protein $\times \mathrm{h}$ ) (Fig. 1C, middle panel). Additionally, we measured higher eNAMPT levels in the supernatant of primary human hepatocytes $(3.2 \pm 0.3 \mathrm{ng} / \mathrm{mg}$ protein) than in HepG2 cells $(0.4 \pm 0.2 \mathrm{ng} / \mathrm{mg}$ protein) (Fig. 1G, right panel).

\section{Resveratrol Induces Cell Cycle Arrest and Apoptosis in Hepatocarcinoma Cells}

Resveratrol has been shown to induce growth arrest and apoptosis in many different cancer cell lines. In the present study, we wanted to investigate whether the effects of resveratrol are p53-dependent. Therefore, we used HepG2 cells, known to be p53 wild-type, Hep3B cells - a p53 deficient cell line due to a deletion of the p53 gene, and primary human hepatocytes as non-cancerous hepatocyte control. Cells were treated with resveratrol as described above. After $24 \mathrm{~h}$, hepatocarcinoma 
A

HepG2 cells

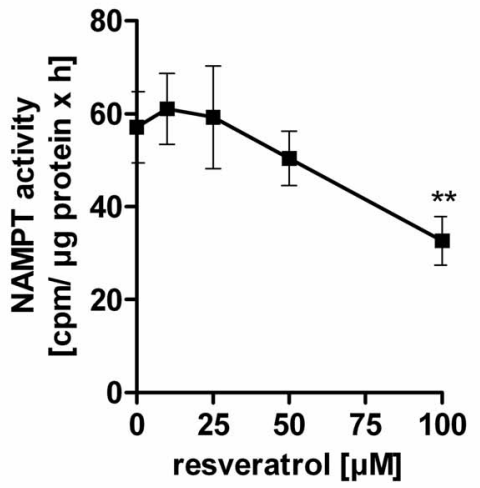

C

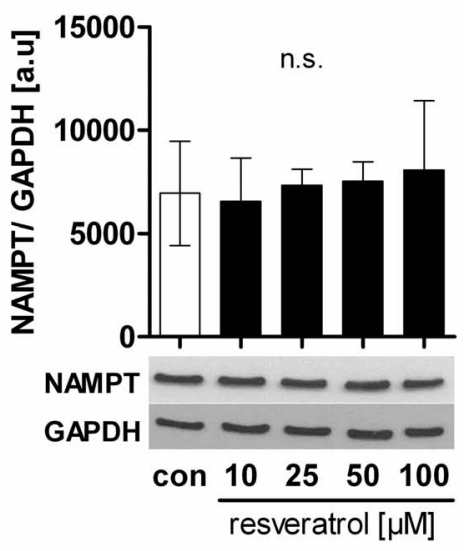

E

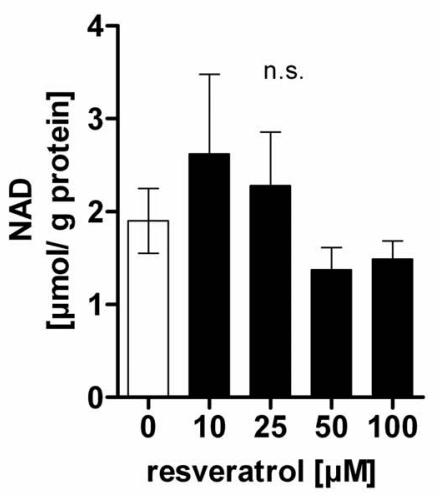

B

\section{primary hepatocytes}

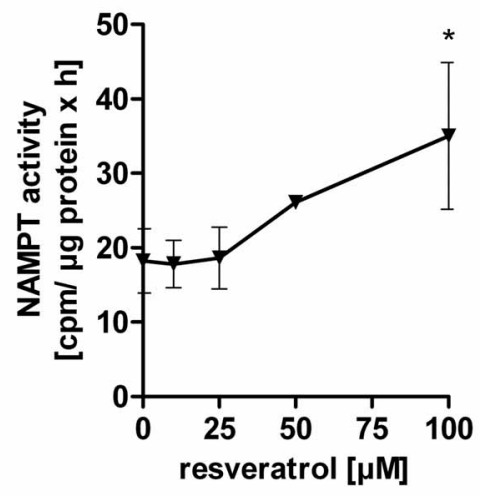

D

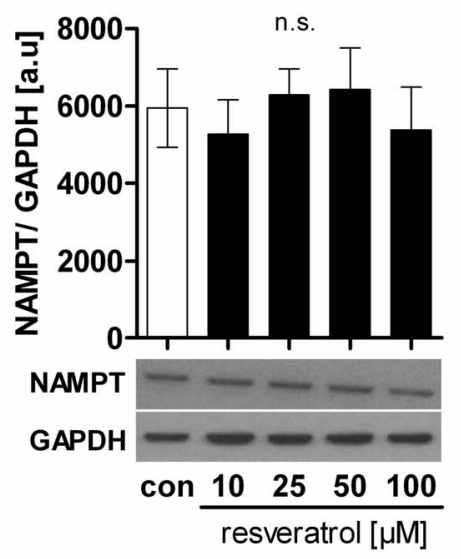

$\mathbf{F}$

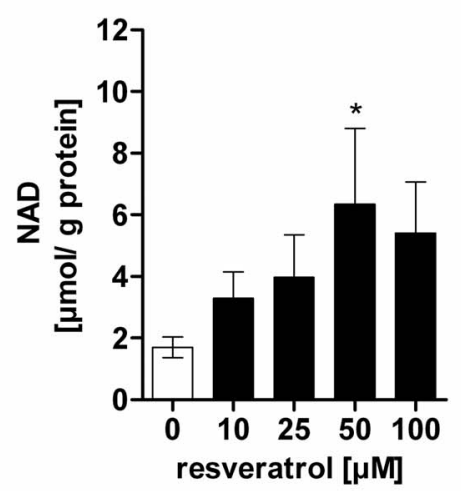

Figure 5. Resveratrol differentially regulates NAMPT and NAD levels in HepG2 cells and primary human hepatocytes. Cells were stimulated with resveratrol or serum-free medium (con) for $24 \mathrm{~h}$. For measuring NAMPT enzymatic activity in A) HepG2 cells and ( $n=4$ ) B) primary human hepatocytes $(n=3), 50 \mu \mathrm{g}$ of protein lysate was used for the assay and incubated for $1 \mathrm{~h}$. Counts (cpm) were normalised to $\mu \mathrm{g}$ total protein. Lysates from C) HepG2 cells $(n=3)$ and D) primary human hepatocytes $(n=3)$ were used to measure NAMPT protein levels by Western Blot. Determination of intracellular NAD levels in E) HepG2 cells $(n=6)$ and F) primary human hepatocytes $(n=4)$. NAD levels were normalised to total protein amount in each sample.

doi:10.1371/journal.pone.0091045.g005

cells showed a dose-dependent decrease in viability (Fig. 2A). Resveratrol $[100 \mu \mathrm{M}]$ markedly decreased cell viability by $45.8 \pm 2.7 \%(\mathrm{p}<0.05)$ in HepG2 cells and by $63.7 \pm 3.4 \%(\mathrm{p}<$ 0.01 ) in Hep3B cells (Fig. 2A). Primary human hepatocytes treated with the same concentrations of resveratrol exhibited no significant changes in viability (Fig. 2A). To investigate the cause of cell viability reduction by resveratrol, we analysed cell cycle distribution. As shown in Fig. 2B, resveratrol [25, $50 \mu \mathrm{M}$ ] 
A

HepG2 cells
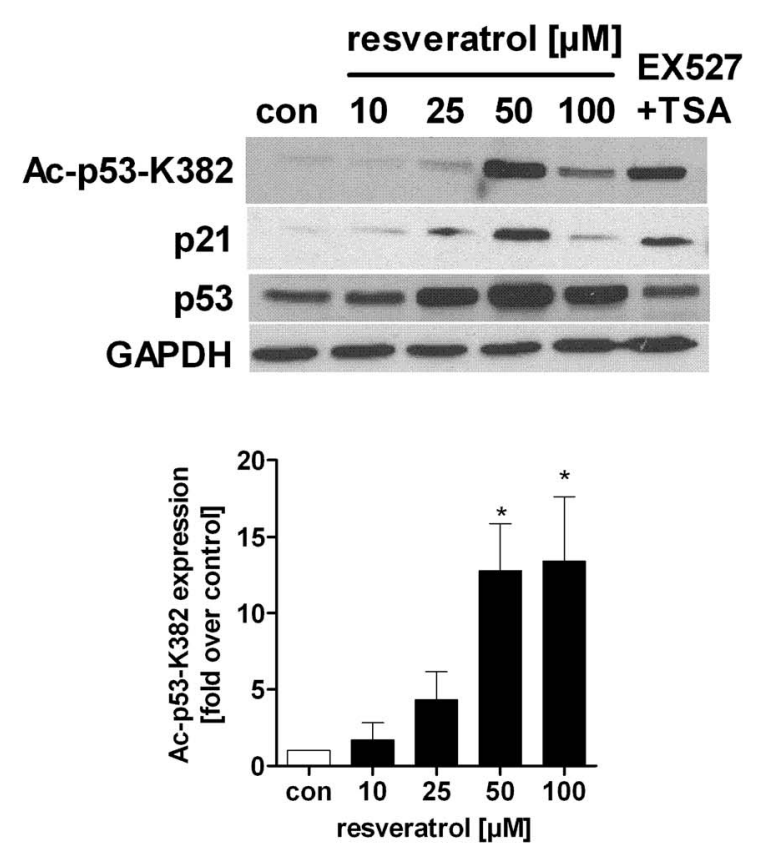

C

HepG2 cells
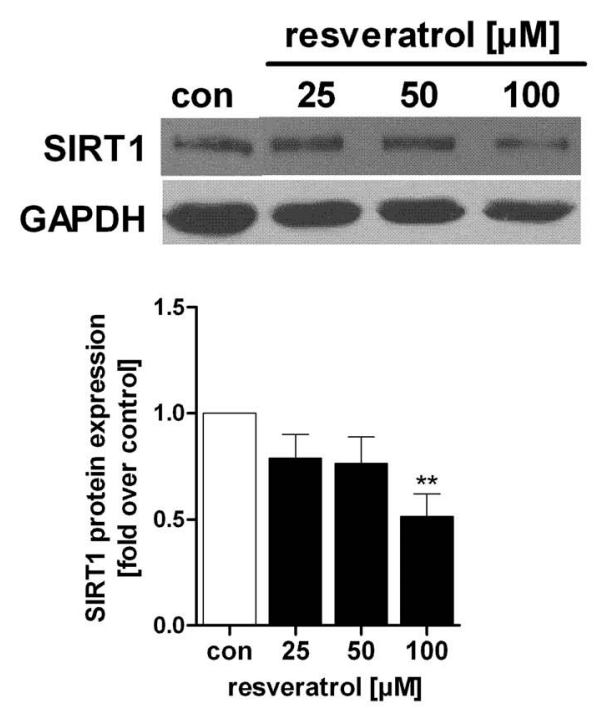

B

primary hepatocytes
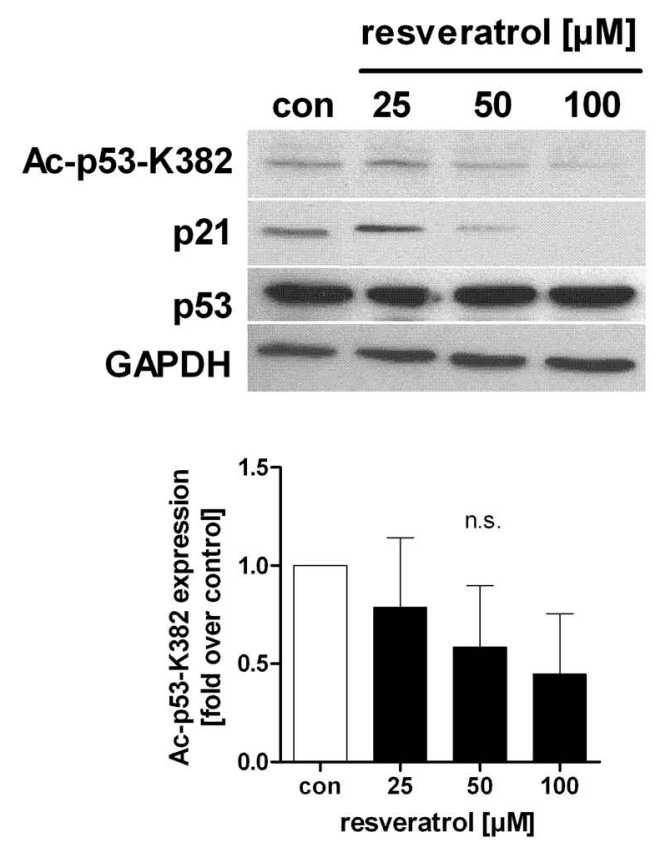

primary hepatocytes
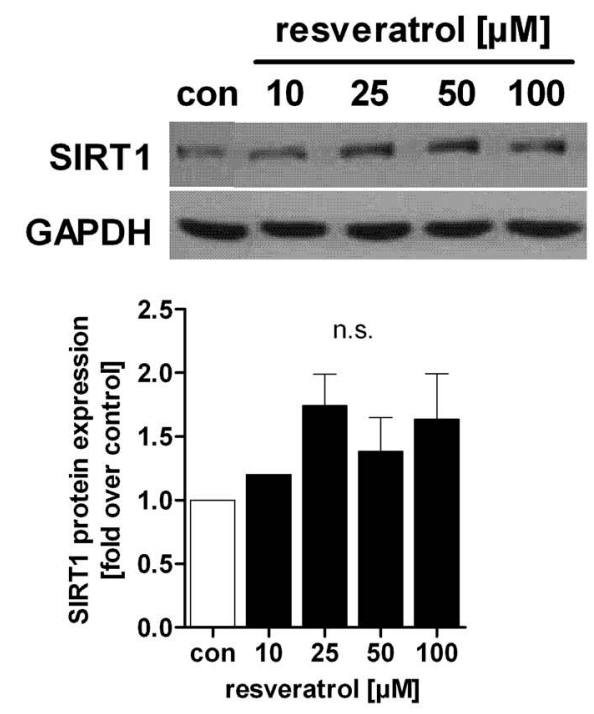

Figure 6. Resveratrol differentially regulates p53 acetylation and SIRT1 protein level in HepG2 cells and primary human hepatocytes. Acetylation of p53 (K382) in A) HepG2 cells $(n=4)$ and B) primary human hepatocytes $(n=3)$ was evaluated by Western Blot. Densitometric analysis of at least three independent experiments is shown. Data are represented as mean \pm SEM and statistical analysis was performed using one-way ANOVA and the Bonferroni post hoc test ${ }^{*} \mathrm{p}<0.05$, n.s. not significant). As a downstream target of acetylated and activated p53, the expression of p21 was analysed by Western Blot. As positive control for SIRT1 inhibition, EX527+TSA was used. SIRT1 protein expression was analysed by Western Blot in C) HepG2 cells and D) primary hepatocytes and densitometric analysis was performed. GAPDH was used as loading control, respectively. One representative blot out of at least 3 independent experiments is shown.

doi:10.1371/journal.pone.0091045.g006

caused an increase of cells in the S-phase ([con] $4.7 \pm 0.6 \%$, $[25 \mu \mathrm{M}] 21.7 \pm 5.1 \%,[50 \mu \mathrm{M}] 17.0 \pm 2.6 \%, \mathrm{p}<0.05)$ and in the G2/M-phase ([con] $13.7 \pm 1.8 \%,[25 \mu \mathrm{M}] 23.9 \pm 4.2 \%,[50 \mu \mathrm{M}]$ $27.0 \pm 6.1 \%, \mathrm{p}<0.05)$ and a corresponding decrease of cells in the G1-phase. The cell cycle distribution was not significantly modified in p53-deficient Hep3B cells (Fig. S2A), which indicates that the resveratrol-induced cell cycle arrest is mediated by a functional p53. However, in both hepatocarcinoma cell lines apoptotic mechanisms were activated. As indicated in Fig. 2C, stimulation with increasing concentrations 
A

HepG2 cells

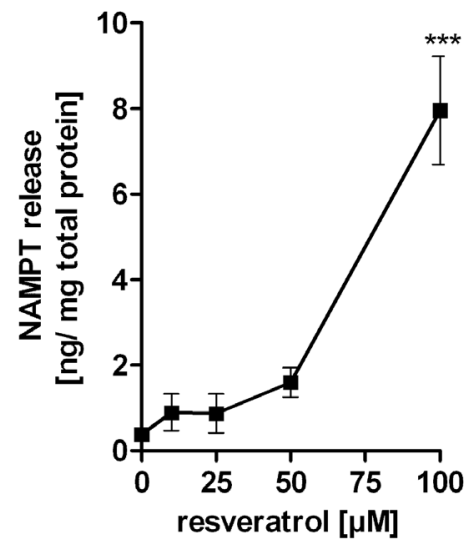

C

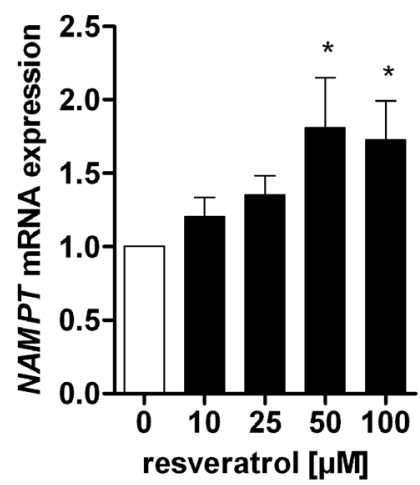

B

\section{primary hepatocytes}

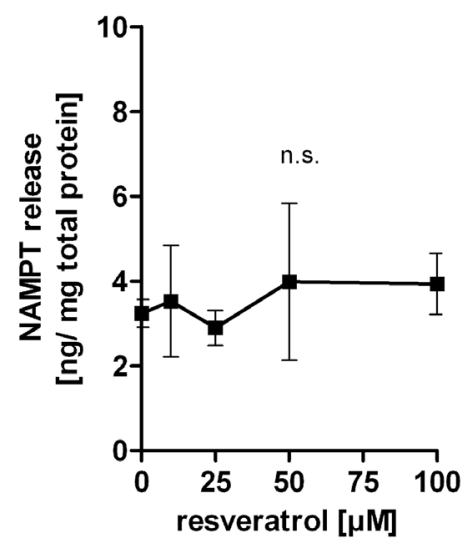

D

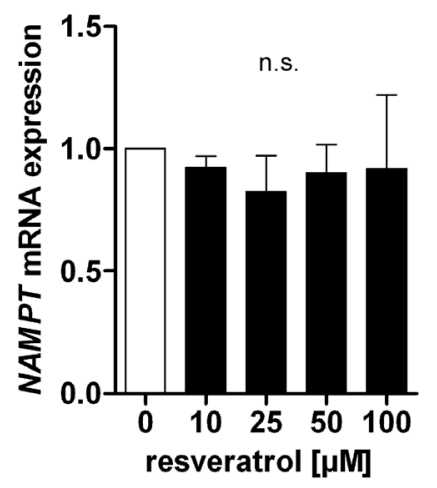

E

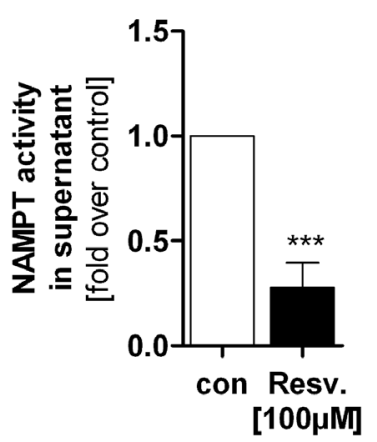

Figure 7. Effects of resveratrol on NAMPT release and NAMPT mRNA expression. Cells were stimulated with resveratrol in serum-free medium for 24 h. Supernatants of resveratrol treated A) HepG2 cells $(n=7)$ and B) primary human hepatocytes $(n=3)$ were used for quantifying extracellular NAMPT protein amount using a specific eNAMPT ELISA. eNAMPT protein concentration was normalised to the total protein amount. NAMPT mRNA expression in resveratrol treated C) HepG2 cells $(n=5)$ and D) primary human hepatocytes $(n=4)$ was quantified by qRT-PCR and normalised to housekeeping genes. NAMPT gene expression was then related to its expression in serum-free control medium (0), which was set 1. Data are represented as mean \pm SEM and statistical analysis was performed using one-way ANOVA and the Bonferroni post hoc test $\left({ }^{*} \mathrm{p}<0.05 ; * * \mathrm{*} p<\right.$ 0.001 ; n.s. not significant). E) Supernatant of resveratrol [100 $\mu \mathrm{M}]$ or serum-free medium (con) treated HepG2 cells was used to measure NAMPT enzymatic activity and extracellular NAMPT protein levels. Counts (cpm) measured by NAMPT enzyme assay were referred to densitometric data of NAMPT protein levels in the supernatant of the same sample. Data were then normalised to serum-free control medium which was set 1 . Data are shown as mean \pm SEM. The difference between these two groups was evaluated using unpaired Student's $t$-test $\left({ }^{* * *} p<0.001\right)$. doi:10.1371/journal.pone.0091045.g007

of resveratrol led to a dose-dependent increase in the number of apoptotic cells in HepG2 (Fig. 2C,D) and Hep3B cells (Fig. 2C). At $100 \mu \mathrm{M}$ resveratrol, the percentage of apoptotic cells in
HepG2 cells and Hep3B cells increased to $40.6 \pm 5.6 \%(\mathrm{p}<0.01)$ and to $32.2 \pm 3.7 \%(\mathrm{p}<0.05)$, respectively. 
A

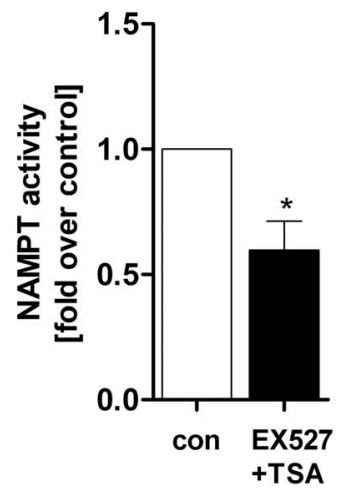

B

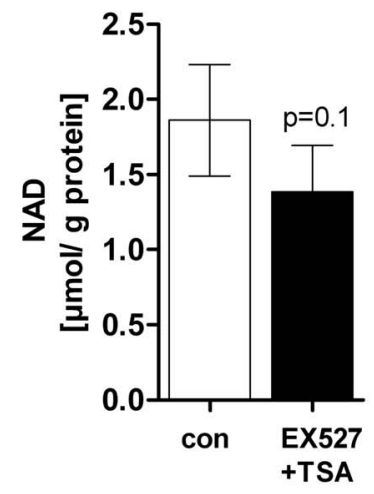

C

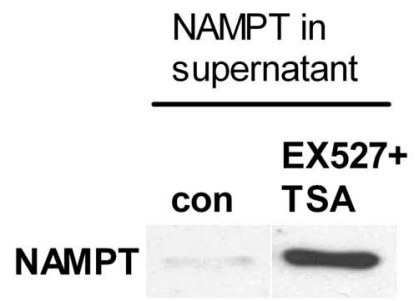

Figure 8. SIRT1 inhibition downregulates NAMPT activity and induces NAMPT release in HepG2 cells. HepG2 cells were treated with EX527+TSA [20 $\mu \mathrm{M}$ EX527+1 $\mu \mathrm{M} \mathrm{TSA}$ ] or serum-free medium (con) for $24 \mathrm{~h}$. Measurement of A) NAMPT enzymatic activity ( $\mathrm{n}=3$ ). Counts (cpm) were normalised to $\mu \mathrm{g}$ total protein in each sample $\left({ }^{*} p<0.05\right)$. B) NAD level were determined by HPLC $(n=5)$ and normalised to total protein amount in each sample. C) Supernatant of EX527 treated HepG2 cells was used for determination of eNAMPT level. One representative Western blot out of 3 independent experiments is shown.

doi:10.1371/journal.pone.0091045.g008

p53 and Caspase-3 are Involved in Resveratrol-mediated Apoptotic Effects

In HepG2 cells, resveratrol increased the phosphorylation of p53 at residue serine 15 in a dose-dependent manner (Fig. 3A). At high concentration of resveratrol $[100 \mu \mathrm{M}]$, we found increased cleavage of caspase-3 (Fig. 3A). The activation of caspase-3 by resveratrol was also increased in p53-deficient Hep3B cells even at lower concentration [25, $50 \mu \mathrm{M}]$ (Fig. 3B). These results indicate that resveratrol induces caspase- 3 activation in a p53-independent manner. Then, we stimulated primary human hepatocytes with the same concentrations of resveratrol and found no induction of apoptosis (Fig. 3C) or cytotoxicity (Fig. S3A).

\section{Inhibition of NAMPT and SIRT1 Activity in Hepatocarcinoma Cells Induces Growth Arrest and Apoptosis}

Several studies have shown that the NAD metabolism is essential for cancer cell survival and proliferation [40-42]. However, little is known about the effects of resveratrol on NAMPT and SIRT1 activity in hepatocarcinoma cells. Human SIRT 1 targets and deacetylates the p53 tumor suppressor protein $[16,17,34]$. Therefore, we investigated whether a specific inhibition of NAMPT and SIRT1 would affect cell survival and apoptotic mechanisms. We used the specific NAMPT inhibitor FK866 and the SIRT1 inhibitor EX527 [34]. FK866 increased p53 acetylation (K382) (Fig. 4A) and reduced HepG2 cell viability after $48 \mathrm{~h}$ (Fig. 4B). Cells treated with the SIRT1 inhibitor, EX527, showed also increased p53 acetylation (K382), enhanced expression of p53 downstream target p21/WAF1/Cip1 and activation of caspase-3 (Fig. 4C).

\section{Resveratrol Differentially Regulates NAMPT Enzymatic Activity in Hepatocarcinoma Cells and Primary Human Hepatocytes}

Based on our findings that an inhibition of NAMPT and SIRT1 activity induced growth arrest and apoptosis in hepatocarcinoma cells we then asked whether resveratrol would also affect NAMPT enzyme activity as well as intracellular NAD levels. We found that resveratrol differentially regulated NAMPT activity in hepatocarcinoma cells (Fig. 5A) and primary hepatocytes (Fig. 5B) without affecting NAMPT protein expression (Fig. 5C,D). We measured a dose-dependently decreased NAMPT activity in HepG2 cells $([100 \mu \mathrm{M}]-38.9 \pm 14.0 \%, \mathrm{p}<0.01)$ (Fig. $5 \mathrm{~A})$ and in Hep3B cells $([100 \mu \mathrm{M}]-38.5 \pm 9.4 \%, \mathrm{p}<0.05)$ (Fig. S4). In contrast, NAMPT enzymatic activity in primary hepatocytes significantly increased by $+64.7 \pm 13.8 \% \quad(\mathrm{p}<0.05)$ after stimulation with $100 \mu \mathrm{M}$ resveratrol (Fig. 5B). We then measured the NAD level after resveratrol treatment in HepG2 cells and found a trend towards reduction ([con] $2.0 \pm 0.4 \mu \mathrm{mol} \mathrm{NAD} / \mathrm{g}$ total protein, $[100 \mu \mathrm{M}]$ $1.5 \pm 0.2 \mu \mathrm{mol} \mathrm{NAD} / \mathrm{g}$ total protein) (Fig. 5E). In contrast, intracellular NAD levels in primary hepatocytes were increased by resveratrol ([con] $1.7 \pm 0.3 \mu \mathrm{mol} \mathrm{NAD/g}$ total protein, $[50 \mu \mathrm{M}]$ $6.4 \pm 2.5 \mu \mathrm{mol} \mathrm{NAD} / \mathrm{g}$ total protein $(\mathrm{p}<0.05), \quad[100 \mu \mathrm{M}]$ $5.4 \pm 1.7 \mu \mathrm{mol} \mathrm{NAD} / \mathrm{g}$ total protein) (Fig. $5 \mathrm{~F}$ ).

Resveratrol Differentially Regulates p53 Acetylation and SIRT1 Protein in Hepatocarcinoma Cells and Primary Human Hepatocytes

We further addressed whether resveratrol could influence p53 acetylation at lysine residue 382 , a main target site of SIRT1 $[16,17,34]$, and demonstrated that resveratrol treatment of HepG2 cells increased acetylation of p53 $([50 \mu \mathrm{M}]$ 12.8-fold, $[100 \mu \mathrm{M}]$ 13.4-fold) (Fig. 6A). As positive control for SIRT1 inhibition, we used the specific SIRT1 inhibitor EX527 [34,37] (Fig. 6A). In contrast, primary human hepatocytes from different donors showed a trend towards reduced p53 acetylation after resveratrol stimulation (Fig. 6B). Since the acetylation of p53 activates its transcriptional activity, we analysed the expression of the p53 downstream target $\mathrm{p} 21 / \mathrm{WAF} 1 / \mathrm{Cip} 1$, which functions as a regulator of cell cycle progression. In correspondence to the acetylation state of p53 we found increased expression of p21 mRNA (Fig. S5A) and protein in HepG2 cells (Fig. 6A). Primary human hepatocytes from different donors showed variable results with either no changes in $\mathrm{p} 21$ protein expression or a p21 down regulation (Fig. 6B, Fig. S5B). Nonetheless, we can exclude an activation of p53 in primary human hepatocytes. Furthermore, SIRT1 protein levels in HepG2 cells were reduced at $100 \mu \mathrm{M}$ resveratrol $(\mathrm{p}<0.01)$ (Fig. $6 \mathrm{C}$ ) whereas primary human hepatocytes showed a trend towards increased SIRT1 protein expression at the same dose of resveratrol (Fig. 6D). Due to the variability of primary hepatocytes the changes were not significant. 
A

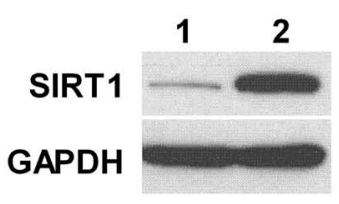

1 mock-control

2 pECE_Flag-SIRT1
B

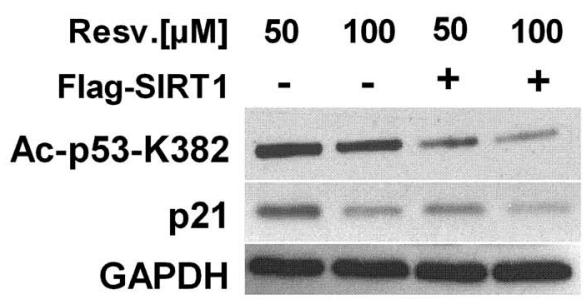

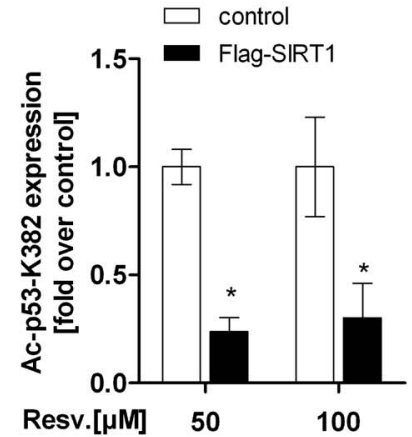

C

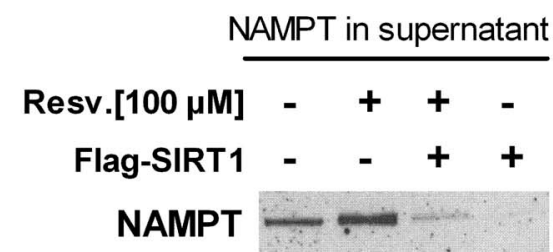

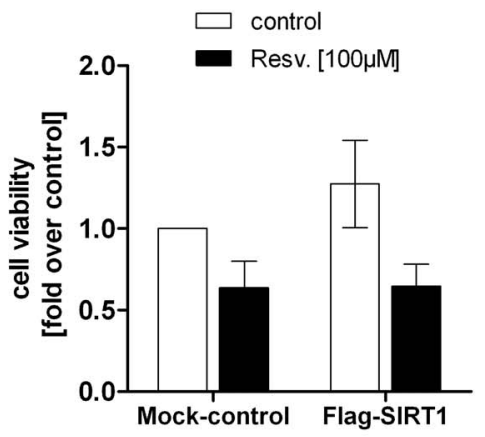

E

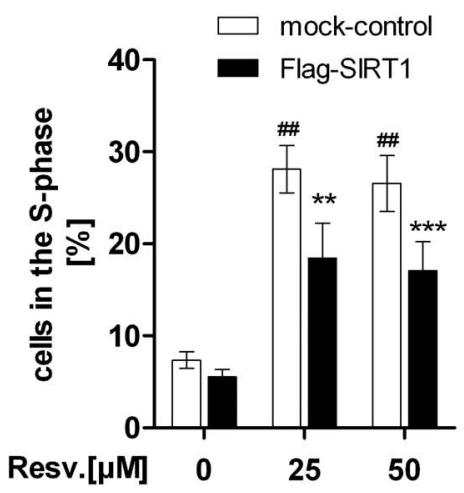

mock-control

con

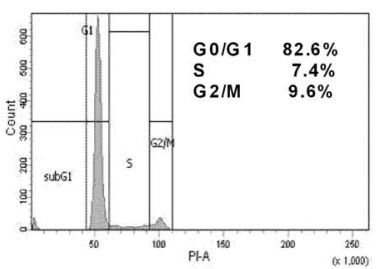

Flag-SIRT1

con

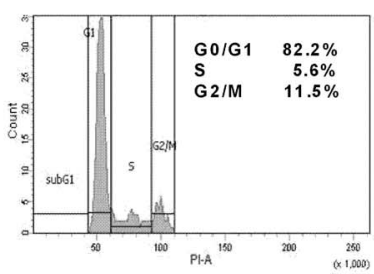

Resv. $25 \mu \mathrm{M}$

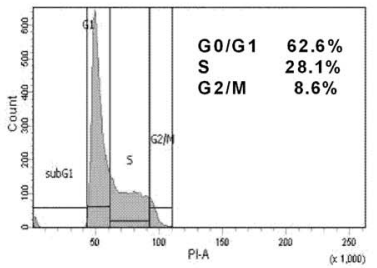

Resv. $25 \mu M$

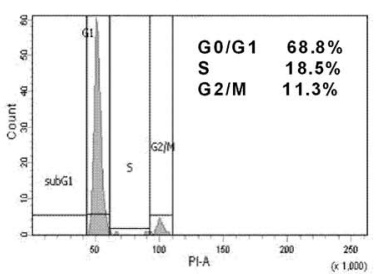

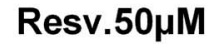

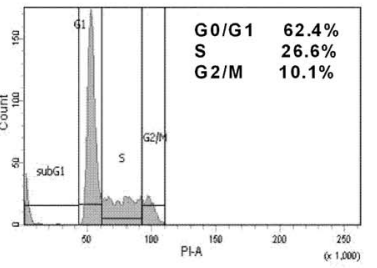

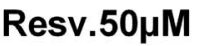

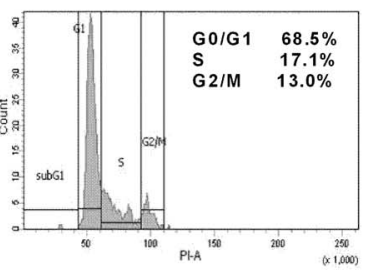

Figure 9. SIRT1 overexpression in HepG2 cells reversed resveratrol-induced SIRT1 inhibition, NAMPT release and S-phase arrest. A) SIRT1 was transiently overexpressed in HepG2 cells $\left[2.0 \mu \mathrm{g}\right.$ plasmid $/ 0.5 \times 10^{6}$ cells] using the expression vector pECE_Flag-SIRT1 from addgene (plasmid 1791; [35]). Lysates of cells transfected with the empty vector pECE (mock-control) (1) or pECE Flag-SIRT1 vector (2) were used for Western Blot analysis. B) mock-transfected (mock-control) and Flag-SIRT1 transfected HepG2 cells were stimulated with resveratrol [50, $100 \mu \mathrm{M}$ Resv.] for $24 \mathrm{~h}$ and Western Blot analysis of acetylated p53 (K382), p21 and GAPDH was performed. Densitometric anaylsis of acetylated p53 of three independent Western Blots is shown. Data were normalised to non-transfected HepG2 cells stimulated with resveratrol alone which was set 1. C) To analyse the effect of SIRT1 overexpression on resveratrol-induced NAMPT release, supernatant of mock-transfected and Flag-SIRT1 transfected HepG2 cells stimulated with or without resveratrol $[100 \mu \mathrm{M}]$ were used to measure eNAMPT level. One representative Western blot out of 3 independent 
experiments is shown. D) Cell viability of mock-transfected and Flag-SIRT1 transfected HepG2 cells treated with resveratrol [100 $\mu$ M] (black bars) was measured using WST-1 assay $(n=3)$. Data were normalised to untreated mock-control which was set 1 . E) mock-transfected (white bars) and FlagSIRT1 transfected HepG2 cells (black bars) were stimulated with resveratrol [25, $50 \mu \mathrm{M}]$ for $24 \mathrm{~h}$. Percentage of cells in the S-phase were measured by $\mathrm{PI}$ staining and FACS analysis. All data are shown as mean \pm SEM $(n=4)$. The difference between two groups was evaluated using unpaired Student's $t$-test (\#\#p<0.01 mock-transfected cells compared to mock-transfected cells treated with resveratrol (white bars, mock-control), ${ }^{* *} \mathrm{p}<0.01,{ }^{* * *} \mathrm{p}<$ 0.001 Flag-SIRT1 transfected cells treated with resveratrol (black bars) compared to resveratrol-treated mock-transfected cells (white bars). doi:10.1371/journal.pone.0091045.g009

\section{Resveratrol Induces NAMPT Release in HepG2 Cells}

Since NAMPT was found to be released from hepatocytes [43] we determined NAMPT concentrations in supernatants from resveratrol-treated HepG2 cells and primary hepatocytes. We measured significantly increased amounts of extracellular NAMPT in the supernatant of HepG2 cells treated with $50 \mu \mathrm{M}$ (4-fold) and $100 \mu \mathrm{M}$ (19.8-fold) resveratrol (Fig. 7A) ([con] $0.4 \pm 0.2 \mathrm{ng} \mathrm{NAMPT} / \mathrm{mg}$ total protein, $[50 \mu \mathrm{M}] 1.6 \pm 0.7 \mathrm{ng}$ $\mathrm{NAMPT} / \mathrm{mg}$ total protein, $[100 \mu \mathrm{M}] 7.9 \pm 1.3 \mathrm{ng}$ NAMPT $/ \mathrm{mg}$ total protein, $\mathrm{p}<0.001)$. We postulated that $\mathcal{N}$ AMPT mRNA expression may be increased following resveratrol exposure in HepG2 cells to maintain a steady-state of intracellular NAMPT protein level. We found a significantly increased $N A M P T$ gene expression after stimulation with $50 \mu \mathrm{M}(1.8$-fold, $\mathrm{p}<0.05)$ and $100 \mu \mathrm{M}(1.7$-fold, $\mathrm{p}<0.05)$ resveratrol in HepG2 cells (Fig. 7C). NAMPT release and NAMPT mRNA expression in primary human hepatocytes were not influenced by resveratrol (Fig. 7B,D). In parallel, a cytotoxicity assay was performed to verify that the increase of extracellular NAMPT levels was not due to leakage from damaged cells (Fig. S3B). We then asked at which time point NAMPT release from HepG2 cells started. We found that there was a time- and dose- dependent release of NAMPT already starting after $6 \mathrm{~h}$ of resveratrol exposure (Fig. S3C). NAMPT is known as a protein with dual function- an enzyme and a cytokine-like function. We asked whether NAMPT that is released after resveratrol exposure could lack NMN biosynthetic action. We found a remarkable decrease in extracellular NAMPT activity by $72.3 \pm 11.9 \%(\mathrm{p}<0.001)$ compared to control cells in serum-free medium (Fig. 7E).

\section{NMN does not Protect Against Resveratrol- induced Apoptosis in Hepatocarcinoma Cells}

Next, we investigated whether NMN would be able to ameliorate resveratrol-mediated effects in HepG2 cells. Interestingly, NMN did not protect from resveratrol-induced cell cycle arrest and apoptosis in hepatocarcinoma cells (Fig. S6A,B,C,D). Further, NMN was not able to abrogate p53 hyperacetylation after resveratrol treatment and to decrease resveratrol-induced NAMPT release in HepG2 cells (Fig. $\mathrm{S} 6 \mathrm{E}, \mathrm{F})$.

\section{SIRT1 Inhibition Decreases NAMPT Activity and Induces NAMPT Release}

Given that resveratrol increased p53 acetylation (K382), downregulated NAMPT activity and induced NAMPT secretion, we asked whether an inhibition of SIRT1 by EX527 would exert the same effects. Indeed, our data revealed that HepG2 cells treated with EX527 showed the same cellular responses as cells stimulated with resveratrol, such as decreased NAMPT enzymatic activity $(-40.3 \pm 11.5 \%, \quad \mathrm{p}<0.05) \quad$ (Fig. $8 \mathrm{~A})$ and slightly reduced intracellular NAD level (Fig. 8B). Further, as observed in resveratrol-treated HepG2 cells, extracellular NAMPT levels were increased upon SIRT1 inhibition (Fig. 8C).

\section{SIRT1 Overexpression Abrogated Resveratrol- induced p53 Hyperacetylation, NAMPT Release and S-phase Arrest}

Since resveratrol and NMN co-treatment did not augment resveratrol-induced p53 hyperacetylation in hepatocarcinoma cells, we tried to overcome this effect by transiently overexpressing SIRT1 in HepG2 cells (Fig. 9A). Our data revealed that SIRT1 overexpression significantly decreased resveratrol- induced p53 hyperacetylation $([50 \mu \mathrm{M}]-76.6 \pm 6.5 \%, \quad[100 \mu \mathrm{M}]-$ $69.9 \pm 15.9 \%, \mathrm{p}<0.05)$ and its transcriptional activity in HepG2 cells (Fig. 9B). We then investigated whether a SIRT1 overexpression would be able to abrogate resveratrol-induced NAMPT secretion in HepG2 cells. SIRT1 overexpressing HepG2 cells treated with $100 \mu \mathrm{M}$ resveratrol led to decreased eNAMPT levels in the supernatant compared to mock-transfected cells treated with resveratrol alone (Fig. 9C). This suggests that SIRT1 may play a crucial role in the mechanism of resveratrol-induced NAMPT secretion. Reduction in cell viability upon resveratrol treatment $[100 \mu \mathrm{M}]$ was not abolished by SIRT1 overexpression (Fig. 9D) indicating that apoptosis inducing factors were still activated and not dependent on SIRT1. However, the resveratrol- induced cell cycle arrest in the S-phase was significantly decreased after SIRT1 overexpression ([con] 7.4 $40.9 \%, \quad[$ con $+25 \mu \mathrm{M}] \quad 28.1 \pm 2.6 \%$, $[$ Flag-SIRT $1+25 \mu \mathrm{M}] \quad 18.5 \pm 3.8 \% ; \quad[\mathrm{con}+50 \mu \mathrm{M}] \quad 26.6 \pm 3 \%$, [Flag-SIRT1+50 $\mu \mathrm{M}$ ] 17.1 $23.2 \%$ ) (Fig. 9E).

\section{Discussion}

There is growing in vitro and in vivo evidence demonstrating the inhibitory effects of resveratrol on liver cancer [44-46]. It is known that resveratrol affects numerous signal transduction pathways associated with tumorigenesis [47]. However, the mechanisms how resveratrol selectively modulates proliferation and apoptosis in tumor cells are not fully understood. A recent study demonstrated that resveratrol has the chemical structure to inhibit the activity of different human histone deacetylases (HDACs), important transcriptional and post-translational regulators [48]. We investigated the molecular mechanisms of resveratrol-induced reduction of cell viability in human hepatocellular carcinoma cells and compared the results with non-cancerous primary human hepatocytes. We found that resveratrol selectively induced apoptosis in HepG2 and Hep3B cells, but not in primary hepatocytes. Our data confirm the apoptotic effects of resveratrol on hepatocarcinoma cells independent of p53 function. Furthermore, several other studies reported that resveratrol induced p53independent apoptosis in tumor cells [49,50], indicating that p53 is not an absolute requirement for the apoptotic effect of resveratrol. In contrast, we found an arrest of cells in the S- and G2/M-phase of the cell cycle only in p53 wild-type HepG2 cells and not in Hep3B cells lacking p53, which was also shown by other groups $[7,51,52]$.

Our study revealed that NAMPT and SIRT1 were expressed in an opposite way in hepatocarcinoma cells and primary hepatocytes and were differentially regulated by resveratrol. Other groups found SIRT1 expression to be significantly elevated in hepatocellular carcinoma (HCC) compared to non-cancerous tissues, the expression levels correlated with tumor grades and 
predicted poor prognosis. SIRT1 was shown to promote tumorigenesis in HCG, and inhibition of SIRT1 consistently suppressed the proliferation of HCC cells in vitro or in vivo via the induction of cellular senescence or apoptosis [53-56]. The expression and role of NAMPT in HCG has not been characterised so far. In contrast to findings in other cancer cell types [18], we found that hepatocarcinoma cells express lower levels of NAMPT compared to non-cancerous primary hepatocytes. However, we found that HepG2 cells possess a higher basal NAMPT activity than primary hepatocytes, which goes in line with the comparable NAD levels in both cell types despite weaker NAMPT expression in hepatocarcinoma cells.

Under basal conditions primary hepatocytes released higher amounts of NAMPT into the supernatant than HepG2 cells. As shown by our group, HepG2 cells and primary human hepatocytes constitutively release NAMPT in its dimeric, enzymatically active form [43]. Presumably, due to the higher amount of cellular NAMPT protein in primary human hepatocytes compared to hepatocarcinoma cells, NAMPT is constitutively more released from primary hepatocytes leading to higher basal eNAMPT level. However, we cannot completely preclude, that due to necrosis of fragile or dead primary hepatocytes, proteins are released into the supernatant.

There are several reports showing that resveratrol acts as a natural SIRT1 activator [10,57-60]. We observed increased NAMPT activity and intracellular NAD levels in primary hepatocytes providing evidence for resveratrol as SIRT1 activator in non-cancerous cells. However, recent data showed that resveratrol is not a direct activator of SIRT1 and therefore some mediators are may be involved in this interplay [48,61-63]. Moreover, little is known about NAMPT and SIRT1 regulation by resveratrol in cancer cells. A recent report showed that SIRT1 inhibition is involved in resveratrol-induced cell death in Hodgkin lymphoma (HL)-derived L-428 cells [11]. Additionally, neuroblastoma cells treated with resveratrol also underwent apoptosis and showed a downregulaton of SIRT1 [64]. In our study, resveratrolstimulated HepG2 cells showed similar responses like cells treated with the SIRT1 inhibitor EX527. Thus, we assume that resveratrol is rather acting as a NAMPT and SIRT1 inhibitor in hepatocarcinoma cells. However, there are several reports demonstrating other mechanisms leading to p53 acetylation by resveratrol $[65,66]$.

Our findings indicate that NMN did not ameliorate resveratrolinduced effects on apoptosis, cell cycle arrest and NAMPT release, suggesting that the availability of NAD is not a limiting factor in this scenario. A variety of posttranslational modifications in SIRT1 $\mathrm{N}$ - and C-terminal extensions have been reported, effecting SIRT1 enzyme activity and protein interactions [67,68]. Our findings raise the possibility that, in some cases, the regulation of SIRT1 by other proteins may be more important than NAD availability. Increase in p53 transcriptional activity and induction of S-phase arrest observed upon treatment with resveratrol were abrogated upon SIRT1 overexpression. However, SIRT1 overexpression was not able to augment reduced cell viability in HepG2 cells under high resveratrol concentrations. Resveratrol affects a multitude of other signal transduction pathways associated with apoptotic mechanisms and transcriptional regulation $[66,69]$ that are still activated and not SIRT1 dependent [64]. Thus, these collective activities, rather than just a single effect, may account for the anticancer properties of resveratrol. However, our data give evidence that resveratrol regulates NAMPT activity in cancer cells and non-cancerous cells. Resveratrol could regulate NAMPT enzymatic activity by at least two hypothetical mechanisms: i) by direct interaction inducing conformational changes that lead to alterations of enzymatic activity, or ii) by inducing a posttranslational modification of NAMPT. Our study revealed that SIRT1 inhibition downregulates NAMPT activity and induces NAMPT secretion. This provides the basis for further mechanistic studies on NAMPT-SIRT1 interaction and their regulation.

Further, we found a time- and dose-dependent NAMPT release after resveratrol stimulation of HepG2 cells which was associated with increased NAMPT mRNA expression. The association of increased NAMPT release and mRNA expression has also been shown by Kover et al. in human islets [70]. eNAMPT has been described to act as a cytokine (as pre-B cell colony enhancing factor, PBEF) [71] or as an adipokine (visfatin) [72,73] but also has extracellular enzymatic function to yield NMN [74]. To our knowledge, for the first time our data point to SIRT1 as regulator of NAMPT secretion and NAMPT enzymatic activity in the supernatant. We could show that the resveratrol-induced NAMPT release was significantly reduced after SIRT1 overexpression, indicating a crucial role for SIRT1 in resveratrol-mediated NAMPT secretion.

In summary, our study revealed that resveratrol selectively induced p53-independent cell death in hepatocarcinoma cells and differentially regulated NAMPT and SIRT1 in cancer cells and non-cancerous cells. Our data give evidence that in contrast to normal hepatocytes, resveratrol does not act as a NAMPT and SIRT1 activator in hepatocarcinoma cells. However, it remains to be investigated whether NAMPT interacts with SIRT1 and how it is regulated by resveratrol or other mediators and linked to cellular metabolism and apoptosis. This will provide novel insights concerning the potential of NAMPT and SIRT1 as therapeutic targets in hepatocellular carcinoma.

\section{Supporting Information}

Figure S1 Establishment of parameters for a NAMPT enzymatic assay. Assay conditions, such as A) protein amount, B) $\mathrm{pH}$ value and $\mathrm{C}$ ) incubation time were optimized for measuring NAMPT enzymatic activity. D) We validated the assay performance by adding the specific NAMPT inhibitor FK866 to the lysate before measuring NAMPT activity. As expected, FK866 induced a dose-dependent decrease in NAMPT activity with an $\mathrm{IC}_{50}$ value of $8.2 \mathrm{nM}$. Experiments were performed in HepG2 cells. Data are presented as mean \pm SEM.

(TIF)

Figure S2 Gell cycle arrest in Hep3B and a representative dot plot of HepG2 cells. A) PI staining of cell cycle distribution of Hep3B cells $(n=2)$ stimulated with different concentration of resveratrol $[25 / 50 / 100 \mu \mathrm{M}]$ for $24 \mathrm{~h}$. B) A representative dot plot of cell cycle analysis of HepG2 cells. The left plot shows pulse width versus area; this is the plot used to distinguish between single cells and aggregates. Single cells have been gated and a FL2-Area histogram has been drawn and formatted to show only the events inside of the single cell region. (TIF)

Figure S3 Resveratrol does not have cytotoxic effects on HepG2 cells and primary human hepatocytes. HepG2 cells and primary human hepatocytes were stimulated with resveratrol $[10 / 25 / 50 / 100 \mu \mathrm{M}]$ in serum-free medium for $24 \mathrm{~h}$ and supernatant was used for the ToxiLight Non-destructive Cytotoxicity BioAssay. A) Primary human hepatocytes $(\mathrm{n}=3)$ and B) HepG2 cells $(n=3)$ showed no cytotoxic effects after stimulation with resveratrol. Data are shown as mean \pm SEM. Statistical analysis was performed using one-way ANOVA and the 
Bonferroni post hoc test (n.s. not significant). C) Supernatants of resveratrol $[100 \mu \mathrm{M}]$ or serum-free medium (con) treated HepG2 cells after 6, 12 and $24 \mathrm{~h}$ were used to measure extracellular NAMPT levels by Western Blot.

(TIF)

Figure S4 Resveratrol downregulates NAMPT enzymatic activity in Hep3B cells. Hep3B cells were stimulated with resveratrol $[10 / 25 / 50 / 100 \mu \mathrm{M}]$ in serum-free medium for $24 \mathrm{~h}$. NAMPT enzymatic activity was measured by the conversion of ${ }^{14} \mathrm{C}$ - labelled nicotinamide to ${ }^{14} \mathrm{C}-\mathrm{NMN}$ (see Material and Methods). Counts (cpm) were normalised to $\mu \mathrm{g}$ total protein in each sample measured by BCA protein assay. Data are represented as mean \pm SEM and statistical analysis was performed using one-way ANOVA and the Bonferroni post hoc test ${ }^{*} \mathrm{p}<$ $0.05)$.

(TIF)

Figure S5 p21 and Bax expression in HepG2 cells and primary human hepatocytes. HepG2 cells and primary human hepatocytes were stimulated with resveratrol [10/25/50/ $100 \mu \mathrm{M}]$ in serum-free medium (0) for $24 \mathrm{~h} . \quad p 21 \mathrm{mRNA}$ expression in A) HepG2 cells $(\mathrm{n}=3)$ and $\mathrm{B})$ primary human hepatocytes $(n=4)$. C) Lysates of HepG2 cells $(n=3)$ were used for Western Blot analysis of Bax protein expression. GAPDH was used as loading control. One representative blot out of 3 independent experiments is shown.

(TIF)

Figure S6 NMN does not ameliorate resveratrol-mediated effects on cell viability, NAMPT activity, NAMPT release and p53 hyperacetylation. Given that resvertarol down-regulates NAMPT and increases p53 acetylation in hepatocarcinoma cells which was absent in primary hepatocytes we hypothesised that the administration of NMN, the reaction product of NAMPT and a precursor of NAD, is able to ameliorate the resveratrol-mediated effects by increasing SIRT1 activity. At

\section{References}

1. Bishayee A, Politis T, Darvesh AS (2010) Resveratrol in the chemoprevention and treatment of hepatocellular carcinoma. Cancer Treat Rev 36: 43-53.

2. Jang M, Cai L, Udeani GO, Slowing KV, Thomas CF, et al. (1997) Cancer chemopreventive activity of resveratrol, a natural product derived from grapes. Science 275: 218-220.

3. Delmas D, Lancon A, Colin D, Jannin B, Latruffe N (2006) Resveratrol as a chemopreventive agent: a promising molecule for fighting cancer. Curr Drug Targets 7: 423-442.

4. Delmas D, Solary E, Latruffe N (2011) Resveratrol, a phytochemical inducer of multiple cell death pathways: apoptosis, autophagy and mitotic catastrophe. Curr Med Chem 18: 1100-1121.

5. Vang O, Ahmad N, Baile CA, Baur JA, Brown K, et al. (2011) What is new for an old molecule? Systematic review and recommendations on the use of resveratrol. PLoS One 6: e19881.

6. Baur JA, Sinclair DA (2006) Therapeutic potential of resveratrol: the in vivo evidence. Nat Rev Drug Discov 5: 493-506.

7. Joe AK, Liu H, Suzui M, Vural ME, Xiao D, et al. (2002) Resveratrol induces growth inhibition, S-phase arrest, apoptosis, and changes in biomarker expression in several human cancer cell lines. Clin Cancer Res 8: 893-903.

8. Baarine M, Thandapilly SJ, Louis XL, Mazue F, Yu L, et al. (2011) Proapoptotic versus anti-apoptotic properties of dietary resveratrol on tumoral and normal cardiac cells. Genes Nutr 6: 161-169.

9. Kuo PL, Chiang LC, Lin CG (2002) Resveratrol- induced apoptosis is mediated by p53-dependent pathway in Hep G2 cells. Life Sci 72: 23-34.

10. Howitz KT, Bitterman KJ, Cohen HY, Lamming DW, Lavu S, et al. (2003) Small molecule activators of sirtuins extend Saccharomyces cerevisiae lifespan. Nature 425: 191-196.

11. Frazzi R, Valli R, Tamagnini I, Casali B, Latruffe N, et al. (2012) Resveratrolmediated apoptosis of hodgkin lymphoma cells involves SIRT1 inhibition and FOXO3a hyperacetylation. Int J Cancer.

12. Bjorklund M, Roos J, Gogvadze V, Shoshan M (2011) Resveratrol induces S. Cancer Chemother Pharmacol 68: 1459-1467. the beginning, we tested whether HepG2 cells are able to utilize exogenous NMN $[500 \mu \mathrm{M}]$ and to synthesize NAD. Therefore, we stimulated the cells with FK866 $[10 \mathrm{nM}]$ to inhibit NAMPT activity and co-stimulated the cells with NMN $[500 \mu \mathrm{M}]$. We could show that FK866 depleted the intracellular NAD levels by $79.4 \pm 3.3 \%$ in HepG2 cells which could be restored by NMN supplementation. A) NAD levels of HepG2 cells $(n=5)$ treated with the NAMPT inhibitor FK866 [10 nM] (white bars) in serumfree medium (con) and NMN [500 $\mu \mathrm{M}]$ (black bars) for $24 \mathrm{~h}$. Annexin V/PI apoptosis assay of B) HepG2 cells $(\mathrm{n}=3)$ and $\mathrm{C}$ ) Hep3B cells $(n=2)$ treated with resveratrol $[25 / 50 / 100 \mu M]$ in serum-free medium and co-stimulated with NMN $[500 \mu \mathrm{M}]$ for 24 h. An+ and An+/PI+ cells were considered apoptotic. Data are represented as mean \pm SEM. Differences between two groups were evaluated using unpaired Student's $t$-test (resvertarol (white bar) compared to resveratrol $+\mathrm{NMN}$ (black bar)). Then $\mathrm{D}$ ) Western Blot analysis of cleaved caspase-3, E) acetylated p53 (K382) and F) eNAMPT levels in supernatant of these cells were performed. One representative blot out of at least 3 independent experiments is shown.

(TIF)

\section{Acknowledgments}

Primary human hepatocytes were kindly provided by the "virtual liver" program, a major national initiative on Systems Biology of the Liver. FK866 was kindly provided by TopoTarget A/S, Copenhagen, Denmark. We thank Prof. Dr. Kurt Engeland for providing Hep3B cells and our technicians Anja Barnikol-Oettler and Sandy Richter as well as Doris Mahn and Frank Struck for excellent work.

\section{Author Contributions}

Conceived and designed the experiments: SS MP SPQ AG WK TG. Performed the experiments: SS MP SPQ AG. Analyzed the data: SS MP SPQ AG TG. Contributed reagents/materials/analysis tools: GD RG SPQ. Wrote the paper: SS.

13. Yang Q, Wang B, Zang W, Wang X, Liu Z, et al. (2013) Resveratrol inhibits the growth of gastric cancer by inducing $\mathrm{g} 1$ phase arrest and senescence in a sirt1dependent manner. PLoS One 8: e70627.

14. Deng CX (2009) SIRT1, is it a tumor promoter or tumor suppressor? Int J Biol Sci 5: 147-152.

15. Liu T, Liu PY, Marshall GM (2009) The critical role of the class III histone deacetylase SIRT1 in cancer. Cancer Res 69: 1702-1705.

16. Vaziri H, Dessain SK, Ng EE, Imai SI, Frye RA, et al. (2001) hSIR2(SIRT1) functions as an NAD-dependent p53 deacetylase. Cell 107: 149-159.

17. Zhang Q, Zeng SX, Zhang Y, Zhang Y, Ding D, et al. (2012) A small molecule Inauhzin inhibits SIRT1 activity and suppresses tumour growth through activation of p53. EMBO Mol Med 4: 298-312.

18. Bi TQ, Che XM (2010) Nampt/PBEF/visfatin and cancer. Cancer Biol Ther 10: $119-125$.

19. Berger F, Ramirez-Hernandez MH, Ziegler M (2004) The new life of a centenarian: signalling functions of $\operatorname{NAD}(\mathrm{P})$. Trends Biochem Sci 29: 111-118.

20. Chiarugi A, Dolle G, Felici R, Ziegler M (2012) The NAD metabolome-a key determinant of cancer cell biology. Nat Rev Cancer 12: 741-752.

21. Houtkooper RH, Canto C, Wanders RJ, Auwerx J (2010) The secret life of $\mathrm{NAD+}$ : an old metabolite controlling new metabolic signaling pathways. Endocr Rev 31: 194-223.

22. Revollo JR, Grimm AA, Imai S (2004) The NAD biosynthesis pathway mediated by nicotinamide phosphoribosyltransferase regulates Sir2 activity in mammalian cells. J Biol Chem 279: 50754-50763.

23. Revollo JR, Grimm AA, Imai S (2007) The regulation of nicotinamide adenine dinucleotide biosynthesis by Nampt/PBEF/visfatin in mammals. Curr Opin Gastroenterol 23: 164-170.

24. Zhang T, Berrocal JG, Frizzell KM, Gamble MJ, DuMond ME, et al. (2009) Enzymes in the NAD+ salvage pathway regulate SIRT1 activity at target gene promoters. J Biol Chem 284: 20408-20417.

25. Ho C, van d, V, Akawi O, Pickering JG (2009) SIRT1 markedly extends replicative lifespan if the NAD+ salvage pathway is enhanced. FEBS Lett 583: 3081-3085. 
26. Hufton SE, Moerkerk PT, Brandwijk R, de Bruine AP, Arends JW, et al. (1999) A profile of differentially expressed genes in primary colorectal cancer using suppression subtractive hybridization. FEBS Lett 463: 77-82.

27. Van Beijnum JR, Moerkerk PT, Gerbers AJ, de Bruine AP, Arends JW, et al. (2002) Target validation for genomics using peptide-specific phage antibodies: a study of five gene products overexpressed in colorectal cancer. Int J Cancer 101: $118-127$.

28. Folgueira MA, Carraro DM, Brentani H, Patrao DF, Barbosa EM, et al. (2005) Gene expression profile associated with response to doxorubicin-based therapy in breast cancer. Clin Cancer Res 11: 7434-7443.

29. Hasmann M, Schemainda I (2003) FK866, a highly specific noncompetitive inhibitor of nicotinamide phosphoribosyltransferase, represents a novel mechanism for induction of tumor cell apoptosis. Cancer Res 63: 7436-7442.

30. Thakur BK, Dittrich T, Chandra P, Becker A, Kuehnau W, et al. (2013) Involvement of p53 in the cytotoxic activity of the NAMPT inhibitor FK866 in myeloid leukemic cells. Int J Cancer 132: 766-774.

31. Drevs J, Loser R, Rattel B, Esser N (2003) Antiangiogenic potency of FK866/ $\mathrm{K} 22.175$, a new inhibitor of intracellular NAD biosynthesis, in murine renal cell carcinoma. Anticancer Res 23: 4853-4858.

32. Muruganandham M, Alfieri AA, Matei C, Chen Y, Sukenick G, et al. (2005) Metabolic signatures associated with a NAD synthesis inhibitor-induced tumor apoptosis identified by $1 \mathrm{H}$-decoupled-31P magnetic resonance spectroscopy. Clin Cancer Res 11: 3503-3513.

33. Thakur BK, Dittrich T, Chandra P, Becker A, Lippka Y, et al. (2012) Inhibition of NAMPT pathway by FK866 activates the function of p53 in HEK293T cells. Biochem Biophys Res Commun 424: 371-377.

34. Solomon JM, Pasupuleti R, Xu L, McDonagh T, Curtis R, et al. (2006) Inhibition of SIRT 1 catalytic activity increases p53 acetylation but does not alter cell survival following DNA damage. Mol Cell Biol 26: 28-38.

35. Brunet A, Sweeney LB, Sturgill JF, Chua KF, Greer PL, et al. (2004) Stressdependent regulation of FOXO transcription factors by the SIRT1 deacetylase. Science 303: 2011-2015.

36. Nussler AK, Nussler NC, Merk V, Brulport M, Schormann W, et al. (2009) The Holy Grail of Hepatocyte Culturing and Therapeutic Use. In: Santin M, editors. Strategies in Regenerative Medicine. New York, USA. 283-320.

37. Peck B, Chen CY, Ho KK, Di Fruscia P, Myatt SS, et al. (2010) SIRT inhibitors induce cell death and p53 acetylation through targeting both SIRT1 and SIRT2. Mol Cancer Ther 9: 844-855.

38. Elliott GC, Ajioka J, Okada CY (1980) A rapid procedure for assaying nicotinamide phosphoribosyltransferase. Anal Biochem 107: 199-205.

39. Ramsey KM, Yoshino J, Brace CS, Abrassart D, Kobayashi Y, et al. (2009) Circadian clock feedback cycle through NAMPT-mediated NAD+ biosynthesis. Science 324: 651-654.

40. Chini CG, Gonzalez GA, Nin V, Camacho-Pereira J, Escande C, et al. (2013) Targeting of NAD metabolism in pancreatic cancer cells: potential novel therapy for pancreatic tumors. Clin Cancer Res.

41. Cagnetta A, Cea M, Calimeri T, Acharya C, Fulciniti M, et al. (2013) Intracellular $\mathrm{NAD}(+)$ depletion enhances bortezomib-induced anti-myeloma activity. Blood 122: 1243-1255.

42. Tan B, Young DA, Lu ZH, Wang T, Meier TI, et al. (2013) Pharmacological inhibition of nicotinamide phosphoribosyltransferase (NAMPT), an enzyme essential for NAD+ biosynthesis, in human cancer cells: metabolic basis and potential clinical implications. J Biol Chem 288: 3500-3511.

43. Garten A, Petzold S, Barnikol-Oettler A, Korner A, Thasler WE, et al. (2010) Nicotinamide phosphoribosyltransferase (NAMPT/PBEF/visfatin) is constitutively released from human hepatocytes. Biochem Biophys Res Commun 391: 376-381.

44. Delmas D, Jannin B, Cherkaoui MM, Latruffe N (2000) Inhibitory effect of resveratrol on the proliferation of human and rat hepatic derived cell lines. Oncol Rep 7: 847-852.

45. De L, V, Monvoisin A, Neaud V, Krisa S, Payrastre B, et al. (2001) Transresveratrol, a grapevine-derived polyphenol, blocks hepatocyte growth factorinduced invasion of hepatocellular carcinoma cells. Int J Oncol 19: 83-88.

46. Carbo N, Costelli P, Baccino FM, Lopez-Soriano FJ, Argiles JM (1999) Resveratrol, a natural product present in wine, decreases tumour growth in a rat tumour model. Biochem Biophys Res Commun 254: 739-743.

47. Aggarwal BB, Bhardwaj A, Aggarwal RS, Seeram NP, Shishodia S, et al. (2004) Role of resveratrol in prevention and therapy of cancer: preclinical and clinical studies. Anticancer Res 24: 2783-2840.

48. Venturelli S, Berger A, Bocker A, Busch C, Weiland T, et al. (2013) Resveratrol as a pan-HDAC inhibitor alters the acetylation status of jistone proteins in human-derived hepatoblastoma cells. PLoS One 8: e73097.

49. Mahyar-Roemer M, Katsen A, Mestres P, Roemer K (2001) Resveratrol induces colon tumor cell apoptosis independently of p53 and precede by epithelial differentiation, mitochondrial proliferation and membrane potential collapse. Int J Cancer 94: 615-622.

50. Gogada R, Prabhu V, Amadori M, Scott R, Hashmi S, et al. (2011) Resveratrol induces p53-independent, X-linked inhibitor of apoptosis protein (XIAP)mediated Bax protein oligomerization on mitochondria to initiate cytochrome $\mathrm{c}$ release and caspase activation. J Biol Chem 286: 28749-28760.

51. Bernhard D, Tinhofer I, Tonko M, Hubl H, Ausserlechner MJ, et al. (2000) Resveratrol causes arrest in the S-phase prior to Fas-independent apoptosis in CEM-C7H2 acute leukemia cells. Cell Death Differ 7: 834-842.

52. Zhou R, Fukui M, Choi HJ, Zhu BT (2009) Induction of a reversible, noncytotoxic S-phase delay by resveratrol: implications for a mechanism of lifespan prolongation and cancer protection. Br J Pharmacol 158: 462-474.

53. Chen J, Zhang B, Wong N, Lo AW, To KF, et al. (2011) Sirtuin 1 is upregulated in a subset of hepatocellular carcinomas where it is essential for telomere maintenance and tumor cell growth. Cancer Res 71: 4138-4149.

54. Chen HC, Jeng YM, Yuan RH, Hsu HC, Chen YL (2012) SIRT1 promotes tumorigenesis and resistance to chemotherapy in hepatocellular carcinoma and its expression predicts poor prognosis. Ann Surg Oncol 19: 2011-2019.

55. Wang H, Liu H, Chen K, Xiao J, He K, et al. (2012) SIRT1 promotes tumorigenesis of hepatocellular carcinoma through PI3K/PTEN/AKT signaling. Oncol Rep 28: 311-318.

56. Portmann S, Fahrner R, Lechleiter A, Keogh A, Overney S, et al. (2013) Antitumor effect of SIRT1 inhibition in human HCC tumor models in vitro and in vivo. Mol Cancer Ther 12: 499-508.

57. Zhang C, Feng Y, Qu S, Wei X, Zhu H, et al. (2011) Resveratrol attenuates doxorubicin-induced cardiomyocyte apoptosis in mice through SIRT1-mediated deacetylation of p53. Cardiovasc Res 90: 538-545.

58. Wang RH, Zheng Y, Kim HS, Xu X, Cao L, et al. (2008) Interplay among BRCA1, SIRT1, and Survivin during BRCAl-associated tumorigenesis. Mol Cell 32: 11-20.

59. Baur JA, Pearson KJ, Price NL, Jamieson HA, Lerin C, et al. (2006) Resveratrol improves health and survival of mice on a high-calorie diet. Nature 444: $337-$ 342.

60. Kaeberlein M, McDonagh T, Heltweg B, Hixon J, Westman EA, et al. (2005) Substrate-specific activation of sirtuins by resveratrol. J Biol Chem 280: 1703817045.

61. Pacholec M, Bleasdale JE, Chrunyk B, Cunningham D, Flynn D, et al. (2010) SRT1720, SRT2183, SRT1460, and resveratrol are not direct activators of SIRT1. J Biol Chem 285: 8340-8351.

62. Hu Y, Liu J, Wang J, Liu Q (2011) The controversial links among calorie restriction, SIRT1, and resveratrol. Free Radic Biol Med 51: 250-256.

63. Beher D, Wu J, Cumine S, Kim KW, Lu SC, et al. (2009) Resveratrol is not a direct activator of SIRT1 enzyme activity. Chem Biol Drug Des 74: 619-624.

64. Pizarro JG, Verdaguer E, Ancrenaz V, Junyent F, Sureda F, et al. (2011) Resveratrol inhibits proliferation and promotes apoptosis of neuroblastoma cells: role of sirtuin 1. Neurochem Res 36: 187-194.

65. Kai L, Samuel SK, Levenson AS (2010) Resveratrol enhances p53 acetylation and apoptosis in prostate cancer by inhibiting MTA1/NuRD complex. Int J Cancer 126: 1538-1548.

66. Dixit D, Sharma V, Ghosh S, Mehta VS, Sen E (2012) Inhibition of Casein kinase-2 induces p53-dependent cell cycle arrest and sensitizes glioblastoma cells to tumor necrosis factor (TNFalpha)-induced apoptosis through SIRT1 inhibition. Cell Death Dis 3: e271.

67. Flick F, Luscher B (2012) Regulation of sirtuin function by posttranslational modifications. Front Pharmacol 3: 29.

68. Kang H, Jung JW, Kim MK, Chung JH (2009) CK2 is the regulator of SIRT1 substrate-binding affinity, deacetylase activity and cellular response to DNAdamage. PLoS One 4: e6611.

69. Whitlock NC, Baek SJ (2012) The anticancer effects of resveratrol: modulation of transcription factors. Nutr Cancer 64: 493-502.

70. Kover K, Tong PY, Watkins D, Clements M, Stehno-Bittel L, et al. (2013) Expression and regulation of nampt in human islets. PLoS One 8: e58767.

71. Samal B, Sun Y, Stearns G, Xie C, Suggs S, et al. (1994) Cloning and characterization of the cDNA encoding a novel human pre-B-cell colonyenhancing factor. Mol Cell Biol 14: 1431-1437.

72. Fukuhara A, Matsuda M, Nishizawa M, Segawa K, Tanaka M, et al. (2005) Visfatin: a protein secreted by visceral fat that mimics the effects of insulin. Science 307: 426-430.

73. Fukuhara A, Matsuda M, Nishizawa M, Segawa K, Tanaka M, et al. (2007) Retraction. Science 318: 565 .

74. Revollo JR, Korner A, Mills KF, Satoh A, Wang T, et al. (2007) Nampt/PBEF/ Visfatin regulates insulin secretion in beta cells as a systemic NAD biosynthetic enzyme. Cell Metab 6: 363-375. 